This article was published in Applied Catalysis B: Environmental, 154-155, 316-328, 2014 http://dx.doi.org/10.1016/j.apcatb.2014.02.032

\title{
Ultraselective low temperature steam reforming of methanol over PdZn/ZnO catalysts - Influence of induced support defects on catalytic performance
}

Katarzyna Morawa Eblagon ${ }^{a}$, Patricia Heydorn Concepción ${ }^{b}$, Hugo Silva ${ }^{a}$, Adélio Mendes ${ }^{\mathrm{a}, *}$

a Faculty of Chemical Engineering, University of Porto, Rua Doutor Roberto Frias s/n, 4200-465 Porto, Portugal

b Instituto de Tecnologíia Química, Universitat Politecnica de Valencia (UPVCSIC) , Avenida de los Naranjos s/n, 46022 Valencia, Spain

* Corresponding author. Tel.: +351 225081695.

E-mail addresses: k.eblagon@fe.up.pt (K.M. Eblagon), pconcepc@upvnet.upv.es (P.H. Concepción), silva.hugo@fe.up.pt (H. Silva), mendes@fe.up.pt (A. Mendes). 


\section{Abstract}

The influence of the calcination atmosphere of $\mathrm{ZnO}$ precursor $(\mathrm{Zn} 4(\mathrm{CO}) 3(\mathrm{OH}) 6 \cdot \mathrm{H} 2 \mathrm{O})$ on the catalytic performance of a series of $\mathrm{PdZn} / \mathrm{ZnO}$ catalysts was studied for production of $\mathrm{H} 2$ via low temperature $\left(180^{\circ} \mathrm{C}\right)$ direct methanol steam reforming (low temperature-MSR). The catalytic activity and selectivity of $\mathrm{PdZn} / \mathrm{ZnO}$ were found to be strongly influenced by the calcination atmosphere of $\mathrm{ZnO}$ precursor and increased from oxidizing to reducing atmosphere, following the order $(\mathrm{O} 2<$ air $<\mathrm{N} 2<\mathrm{H} 2)$. As a result, a very active catalyst was obtained by simply supporting $\mathrm{Pd}$ on $\mathrm{ZnO}$ calcined in H2. Further evidence from XPS and TPR analysis indicated that calcination in reducing atmosphere gave rise to a significant increase in the concentration of oxygen vacancies on the surface of $\mathrm{ZnO}$ support. Thus, the superb performance of the best catalyst was attributed to the defect chemistry of $\mathrm{ZnO}$ support; mainly to the amount of oxygen vacancies present in the interface region, which act as additional active sites for water adsorption and subsequent activation. In addition, the formation of $\mathrm{CO}$ was drastically suppressed by replenishment of oxygen vacancies on $\mathrm{ZnO}$ support. Thus, it is clear that the abundance of specific active sites on $\mathrm{PdZn} / \mathrm{ZnO}$ catalyst is strongly influenced by the preparation route of the $\mathrm{ZnO}$ support. Additionally, the PdZn alloy was discovered to be unstable under prolonged exposure to $\mathrm{CO}$ atmosphere and the stability test under methanol steam reforming conditions showed a $24 \%$ drop in conversion over $48 \mathrm{~h}$ testing period. This phenomena can have detrimental effect on the performance of this type of catalytic systems in continuous prolonged duty cycle time on-stream.

\section{Introduction}

Hydrogen will surely contribute to the world energy market in the mid-term to long-term future [1,2]. However, one of the major obstacles of "Hydrogen Economy" is finding a feasible method to storeand distribute sufficient amount of hydrogen mainly for transportation sector [3]. Recently, reformers that can extract hydrogen from fuels gained increased research interest due to the fact that they can be integrated directly with polymer electrolyte fuel cell (PEMFC). As a result, high purity $\mathrm{H} 2$ can be produced in situ on board of the vehicle via wellestablished steam reforming of alcohols from biomass, or hydrocarbons [4]. In this regard, methanol is a promising hydrogen carrier candidate for the future [5] mainly because it has high $\mathrm{H}$ to $\mathrm{C}$ ratio, low chemical energy bond [6] and can be produced either by reduction $\mathrm{CO} 2$ or from diverse bio-based resources [7]. 
Methanol steam reforming (MSR) is accompanied with side- reactions such as: methanol decomposition (MD), water gas shift (WGS) and reversed water gas shift (RWGS) [8,9]. The extent of these processes depends on the feed composition, reaction conditions and the catalyst used. Due to MD and RWGS reactions being always present, the reformate gas inevitably contains $\mathrm{CO}$ contaminant which even in trace levels can poison the PEMFC anode [2,10]. For example, high temperature PEMFC (HT-PEMFC) using polybenzimidazole membranes working at $180{ }^{\circ} \mathrm{C}$ can only tolerate a maximum of $1-2 \% \mathrm{CO}$ in the anode feed [11]. One approach to decrease the amount of produced $\mathrm{CO}$ is to lower the temperature of MSR to the point at which MD is suppressed and WGS reaction is favored due to the thermodynamics of these processes [9]. A catalyst able to work efficiently at lower temperatures is also cost- effective and desirable taking into consideration the integration between the endothermic MSR and exothermic PEMFC operation. Furthermore, low operating temperatures are beneficial for applications as power supplies for small portable devices, where heat and space management are of primary concern [12]. However, the development of a suitable catalytic system promoting both endothermic MSR and exothermic WGS at reasonably low temperatures (below $200{ }^{\circ} \mathrm{C}$ ) remains a challenge.

$\mathrm{Cu}$ based catalysts are typically used for MSR due to their relatively low cost, very high activity and low $\mathrm{CO}$ production at temperatures below $300{ }^{\circ} \mathrm{C}$ [13]. Thus, several catalyst formulations were studied, such as binary compositions; $\mathrm{Cu} / \mathrm{ZnO}$, $\mathrm{Cu} / \mathrm{SiO} 2, \mathrm{Cu} / \mathrm{CeO} 2$ [4], commercially based $\mathrm{Cu} / \mathrm{ZnO} / y-\mathrm{Al} 2 \mathrm{O} 3$ and its variations with added promoters; $\mathrm{Cu} / \mathrm{ZrO} 2 / \boldsymbol{y}-\mathrm{Al}_{2} \mathrm{O} 3, \mathrm{Cu} / \mathrm{Cr} / \boldsymbol{y}-\mathrm{Al}_{2} \mathrm{O} 3$ [2] or $\mathrm{CuTiP} / y-\mathrm{Al}_{2} \mathrm{O} 3$ [6]. More recently $\mathrm{CuZnGaOx}$ [12] and $\mathrm{CuZn}$ catalyst promoted by rare earth metals such as $\mathrm{Tb}$ and $\operatorname{Pr}[14]$ were reported to have high activity at low temperature MSR. Nevertheless, $\mathrm{Cu}$ based catalysts have some considerable drawbacks which include pyrophoricity and easy deactivation due to thermal instability $[7,15]$ or coke formation [13]. Additionally, these catalysts are sensitive towards condensing steam [6], which results in declining activity and mechanical integrity of the catalytic system under duty cycle conditions [11].

The search for a more suitable catalyst for MSR has led to a discovery that the inherent high selectivity of Pd catalyst towards MD can be drastically switched to high selectivity in MSR by simply changing the material of the support [16]. Apparently, Pd supported on hard-to-reduce oxides $\mathrm{Mx} \mathrm{O} y$ ( $\mathrm{M}=\mathrm{Si}, \mathrm{Al}, \mathrm{Mg}, \mathrm{Zr}, \mathrm{Pr}, \mathrm{Ce}$, La) is highly selective to MD $[17,18]$. On the other hand, $\mathrm{Pd}$ supported on easily reducible oxides such as $\mathrm{ZnO}, \mathrm{Ga} 2 \mathrm{O} 3$ or $\mathrm{In} 2 \mathrm{O} 3$ becomes active and selective in MSR. Unusual behavior of these Pd based catalysts was attributed to a formation 
of alloys PdMe (Me = Zn, Ga, In) upon proper reductive pretreatment, leading to a bifunctional synergism between intermetallic and oxide species which is necessary for a good catalytic performance in MSR $[19,20]$. In addition, the in situ partial oxidation of $\mathrm{PdZn}$ nanoparticles was observed recently to result in the formation of a large interface between the intermetallic PdZn and small $\mathrm{ZnO}$ patches, which improved the selectivity to CO2 in MSR [20]. It is thus evident that the performance of $\mathrm{Pd} / \mathrm{ZnO}$ catalyst is not only dependent on the chemical composition or size of the active species, but it is also governed by the type of active sites present on its surface [21]. Moreover, there was an indication that addition of $\mathrm{Zn}$ to Pt or Pd altered the barriers for C-H cleavage and thus changed the stability of various intermediates in MSR [22]. The PdZn/ZnO interface was found to increase water activation at lower temperatures, therefore promoting $\mathrm{CO}_{2}$ selectivity [23]. However, the role of $\mathrm{ZnO}$ in the performance of $\mathrm{PdZn} / \mathrm{ZnO}$ is not yet fully understood.

$\mathrm{ZnO}$ is an anisotropic oxide which contains intrinsically unstable polar facets with point defects that compensate for a surface dipole moment and non-polar facets which exhibit densely packed $\mathrm{Zn}$ and $\mathrm{O}$ atoms that are electrically neutral [24]. In addition, stronger electronic interaction and facile $\mathrm{PdZn}$ alloy formation was reported on $\mathrm{Pd}$ supported on $\mathrm{ZnO}$ with majority of polar facets exposed on the surface. Furthermore, it was shown previously that the exposure of $\mathrm{ZnO}$ to atmospheric pressure of $\mathrm{H} 2$, can change the concentration of the Schottky defects mainly that of oxygen vacancies [25]. In addition, the creation of defects through reduction modifies the $\mathrm{d}$-band states of a reducible metal oxide (such as $\mathrm{ZnO}$ ) which changes the interaction with the adsorbates [26]. As a result, it can be expected that the increased concentration of oxygen vacancies in $\mathrm{ZnO}$ support might improve the performance of the $\mathrm{PdZn} / \mathrm{ZnO}$ catalyst at low temperature MSR. With this regard, the present work will be focused on the performance of PdZn alloys supported on the $\mathrm{ZnO}$ calcined in $\mathrm{N} 2, \mathrm{O} 2$, air and $\mathrm{H} 2$ in low temperature MSR. The catalytic results will be compared to the performance of PdZn sup- ported on commercial $\mathrm{ZnO}$ (Sigma-Aldrich). The aim is to provide an insight into the influence of the active sites present on the sur- face of $\mathrm{ZnO}$ support on the activity and selectivity of the $\mathrm{PdZn} / \mathrm{ZnO}$ catalytic system. Moreover, thorough catalyst characterization was carried out to gain a better understanding of the key parameters controlling the performance of $\mathrm{PdZn} / \mathrm{ZnO}$ catalysts for low temperature MSR. Thus, the extent of synergetic interaction between $\mathrm{PdZn}$ and various $\mathrm{ZnO}$ was studied using analytical techniques such as X-ray Diffraction (XRD), Temperature Programmed Reduction (TPR) and X-ray Photoelectron Spectroscopy (XPS). Selected catalysts and $\mathrm{ZnO}$ supports were additionally characterised by high resolution transmission electron microscopy (HRTEM) and scanning electron microscopy- 
energy dispersive $X$-ray spectroscopy (SEM-EDX). The active sites and the stability of PdZn/ZnO catalysts was characterised by CO absorption IR DRIFT spectroscopy. Finally, the stability test of the most active catalyst was carried out to access its long term performance under prolonged exposure to methanol steam reforming conditions.

\section{Experimental}

\subsection{Hydrothermal method of ZnOpreparation}

All the reagents were purchased from Sigma-Aldrich and were used without any pretreatment. The $\mathrm{ZnO}$ supports were obtained following a conventional hydrothermal synthesis [27]. $\mathrm{Zn}(\mathrm{CH} 3 \mathrm{COO}) 2$ was used as a $\mathrm{Zn}^{2+}$ precursor, $\mathrm{CO}(\mathrm{NH} 2) 2$ as precipitant and P123 Pluronic block copolymer as a surfactant. In a typical hydrothermal synthesis; $1.1 \mathrm{~g}$ of $\mathrm{Zn}(\mathrm{CH} 3 \mathrm{COO}) 2,6 \mathrm{~g}$ of urea and $3 \mathrm{~g}$ of P123 were dissolved in $100 \mathrm{~mL}$ of distilled water. Subsequently, the $\mathrm{pH}$ of the solution was fixed at 5.0 using $\mathrm{CH} 3 \mathrm{COOH}$ and the mixture was left to homogenize at ambient conditions for $2 \mathrm{~h}$. After a homogenous mixture was obtained, the solution was sealed in a hydrothermal teflon lined reactor and heated in a laboratory oven at $90{ }^{\circ} \mathrm{C}$ for $24 \mathrm{~h}$ to ensure the complete precipitation of zinc carbonate. Subsequently, the obtained solid product was filtered and washed several times with distilled water and dried overnight at $90^{\circ} \mathrm{C}$ in air in an oven. The final step of the preparation of $\mathrm{ZnO}$ supports was the calcination of the prepared precursor at $370{ }^{\circ} \mathrm{C}$, with a heating rate of $4.2^{\circ} \mathrm{C} / \mathrm{min}$ in a flow $(200 \mathrm{~mL} / \mathrm{min})$ of a selected gas $(\mathrm{H} 2, \mathrm{O} 2$, air, N2) and with a dwell time of $0.5 \mathrm{~h}$. The prepared $\mathrm{ZnO}$ supports are hereafter referred as: $\mathrm{ZnO} \mathrm{H} 2-\mathrm{ZnO}$ calcined in $\mathrm{H}_{2} ; \mathrm{ZnO} \mathrm{N} 2-\mathrm{ZnO}$ calcined in $\mathrm{N} 2 . \mathrm{ZnO} C \mathrm{COM}$ is a $\mathrm{ZnO}$ commercial support (Sigma-Aldrich), etc.

\subsection{Synthesis of PdZn/ZnO catalysts}

The 4.7 wt \% PdZn/ZnO catalysts were prepared following a standard wet impregnation technique, using hydrothermally pre- pared $\mathrm{ZnO}$ supports (Section 2.1) and $\mathrm{ZnO}$ commercial support (Sigma-Aldrich, $\mathrm{ZnO}$ nanopowder) for comparison. In a typical procedure, the appropriate amount of $\mathrm{ZnO}$ support was wetted by $10 \mathrm{~mL}$ of chloroform to prepare a slurry. Subsequently, a solution of a calculated amount of palladium acetate (Sigma-Aldrich, reagent grade 98\%) in 5 
$\mathrm{mL}$ of chloroform was added dropwise to the slurry of the $\mathrm{ZnO}$ support under vigorous ultrasonic treatment. The sol- vent was then dried out at ambient conditions under continuous magnetic stirring while placed in a fume hood. PdZn alloy formation is necessary to obtain good catalytic activities in MSR, thus the catalyst reduction temperature was optimized by monitoring various reduction temperatures using an on-line XRD technique. The optimum temperature of PdZn alloy formation was chosen at $400^{\circ} \mathrm{C}$ in $\mathrm{H} 2$ flow $(200 \mathrm{~mL} / \mathrm{min})$, with a heating rate of $4.2^{\circ} \mathrm{C} / \mathrm{min}$ and a dwell time of $2 \mathrm{~h}$.

\subsection{Physicochemical characterization of supports and catalysts}

The physicochemical properties of $\mathrm{ZnO}$ supports were characterised using a variety of methods. The morphology and qualitative composition was obtained from SEM images and EDX, respectively. TheSEM micrographs were recorded using a high resolution (Schottky) environmental scanning electron microscope with X-ray microanalysis and backscattered electron diffraction pattern analysis working at $20 \mathrm{kV}$. Shape and sizes of the particles were obtained using image analysis software (ImageJ). The average diameter of the $\mathrm{ZnO}$ assemblies was obtained measuring at least 100 particles from three different regions of each of the samples. The composition of the supports was studied at a magnification of about $600 \mathrm{k}$. Four different areas of each of the samples were examined by EDX analysis with working distance set at $25 \mathrm{~mm}$, dead time $50 \%$ and a process time of $6 \mathrm{~min}$.

The crystallographic characterisation of $\mathrm{ZnO}$ supports was obtained using the XRD technique. The XRD pattern of the selected samples was collected using a Philips PW1729 diffractometer operating in Bragg-Brentano focusing geometry and using $\mathrm{Cu} K a$ radiation at wavelengths $\mathrm{Cu} \mathrm{Ka1}=154.06 \mathrm{pm}$ and $\mathrm{Cu} K a 2=154.439 \mathrm{pm}$. The data was collected at 20 angles $\left(20-70^{\circ}\right)$, with a step size of $0.02^{\circ}$, step speed of $0.5^{\circ} / \mathrm{min}$ and at $1.25 \mathrm{~s}$ per step. The obtained $\mathrm{X}$-ray scans were compared to those of standard database and the phases were assigned comparing the data available in literature.

BET surface area of $\mathrm{ZnO}$ supports was measured following a standard procedure, obtaining N2 11 point adsorption isotherms at $77 \mathrm{~K}$. Prior to the measurements, the samples were outgassed in vacuum at $300^{\circ} \mathrm{C}$ for $2 \mathrm{~h}$.

The neat $\mathrm{ZnO}$ supports and as-prepared $\mathrm{PdZn} / \mathrm{ZnO}$ catalysts were characterised using a TEM CM 20 (accelerating voltage 310 and $208 \mathrm{kV}$ at nominal magnification) and a HRTEM JEOL 2010 (accelerating voltage $600 \mathrm{kV}$, at 
nominal magnification $590 \mathrm{kV}$ ). For determination of a particle size distribution, not less than 100 particles from different areas of the sample were measured, using the Scandium software from Olympus Soft Imaging Solutions. The determination of the lattice $d$-spacing was carried out using high resolution micrographs of the lattice, taking at least five measurements from different areas of the sample. The estimated error of the measurements was $0.01 \mathrm{~nm}$.

The interaction between metal and support in $\mathrm{PdZn} / \mathrm{ZnO}$ calcined at various atmospheres was probed using X-ray photo- electron spectroscopy (XPS). The XPS analysis was performed using a Kratos AXIS Ultra HSA, with VISION software for data acquisition and CASAXPS and XPSPeak 41 software for data analysis. The analysis was carried out with a monochromatic Al Ka X-ray source $(1486.7 \mathrm{eV})$, operating at $15 \mathrm{kV}(90 \mathrm{~W})$, in FAT mode (Fixed Analyser Transmission), with a pass energy of $40 \mathrm{eV}$ for regions ROI and $80 \mathrm{eV}$ for survey. Data acquisition was performed with a pressure lower than $1.0 \times 10^{-6}$ Pa using a charge neutralization system. The modelling of the spectra was performed using peak fit- ting with Gaussian-Lorentzian (80\%) peak shape and Shirley type background subtraction. The TPR-curves were measured using a quartz flow-through apparatus. Consumption of $\mathrm{H}_{2}$ was obtained using a Balzers GAM-415 quadrupole mass spectrometer. Hydrogen response was calibrated by pulsing $1 \mathrm{~mL}$ of $3 \% \mathrm{H} 2$ in argon and measuring the corresponding response. TPR-conditions: H2/Ar (3 vol $\%$ ), flow $20 \mathrm{~mL} / \mathrm{min}$, heating rate $3^{\circ} \mathrm{C} / \mathrm{min}$ in the temperature range $30-600$ ${ }^{\circ} \mathrm{C}$.

The nature of the $\mathrm{Pd}$ species and the type of active sites present in the prepared $\mathrm{PdZn} / \mathrm{ZnO}$ catalysts was further characterised by CO-chemisorption IR-DRIFT analysis. The IR-DRIFT analysis was carried out using powder catalyst. The spectra of adsorbed $\mathrm{CO}$ were recorded at room temperature $\left(25^{\circ} \mathrm{C}\right)$ with a Nexus 8700 FTIR spectrometer using a DTGS detector with $4 \mathrm{~cm}^{-1}$ resolution. An IR cell allowing in situ treatments under controlled gas atmosphere and temperature was connected to a vacuum system with gas dosing facility. For IR studies the samples were pressed into self-supported wafers and diluted in $\mathrm{ZnO}$ (Sigma-Aldrich) using previously optimised weight ratios. The samples were treated at $300{ }^{\circ} \mathrm{C}$ in a $5 \% \mathrm{H} 2$ in $\mathrm{N} 2$ flow $(15 \mathrm{~mL} / \mathrm{min})$ for $2 \mathrm{~h}$ followed by evacuation at $10^{-4} \mathrm{mbar}$ at $350{ }^{\circ} \mathrm{C}$ for 1 h. After the activation procedure, the samples were cooled down to $25^{\circ} \mathrm{C}$ under dynamic vacuum conditions followed by $\mathrm{CO}$ dosing at increasing pressure (0.4-15 mbar). Several IR-DRIFT spectra were recorded with increasing exposure time, until no further changes were observed in the spectra indicating full CO saturation of the surface. 
The amount of Pd in the samples was determined with an ICP- OES (Vista RL, Varian) after matrix-matched calibration. Not more than $5 \mathrm{mg}$ of the sample was dissolved in $2 \mathrm{~mL}$ of aqua regia. Finally, the solutions were diluted in $50-\mathrm{mL}$ volumetric flasks and the analysis was carried out.

The number of surface $\mathrm{Pd}$ sites was quantified by $\mathrm{CO}$ pulse chemisorption experiments which were conducted using a Micromeritics AutoChem II 2920 analyzer. Catalysts (typically $0.3-0.5 \mathrm{~g}$ ) were loaded in a quartz tube that was placed in the built- in furnace. The temperature in the catalyst layer was controlled using a type-K thermocouple and the flow of gasses was regulated by a built-in mass flow controllers. The catalysts were typically purged with dry helium at $100{ }^{\circ} \mathrm{C}$ for $1 \mathrm{~h}$, followed by reduction in $5 \% \mathrm{H} 2 /$ Ar (flow rate 50 $\mathrm{mL} / \mathrm{min}$ ) at $400{ }^{\circ} \mathrm{C}$ for $2 \mathrm{~h}$ and then it was cooled down to $50^{\circ} \mathrm{C}$. Subsequently, the cleaned sample was exposed to pulses of $0.5-\mathrm{mL} \mathrm{CO}$ until five consecutive pulses yielded identical signal areas. The dispersion of $\mathrm{Pd}$ was estimated from the ratio of the number of moles of surface Pd atoms to the total number of moles of Pd atoms present in the catalyst.

\subsection{Catalytic tests}

The catalytic activity tests of MSR were performed in a fixed bed reactor at pressures between 1 and 1.6 bar, with the following experimental conditions: steam/methanol molar ratio of 1.5 and a contact time of $W / F 0=83 \mathrm{~kg} \mathrm{~mol}^{-1} \mathrm{~s}^{-1}$ (where $W$ is the mass of the catalyst, $200 \mathrm{mg}$ and $F 0$ is the flow rate of methanol). The stainless steel microreactor was placed in an electrically heated furnace and the temperature was controlled inside the furnace as well as in the catalytic bed using a K-type thermocouple inserted into the catalytic bed. Argon was used as carrier gas and the flow of reactants was controlled by mass flow meters and the gas products were analysed by an online mass spectrometer. The concentration of $\mathrm{CO}$ (ppm) in the products was measured directly using an on-line $\mathrm{CO}$ analyser (reading error $2 \mathrm{ppm}$ ). An average of at least 10 measurements was taken to reduce the reading error. Prior to the catalytic test, the catalyst was pre-treated in situ for $2 \mathrm{~h}$ by heating up to $200{ }^{\circ} \mathrm{C}$ in a stream of $\mathrm{Ar}(30 \mathrm{~mL} / \mathrm{min})$. Subsequently, the hydrogen gas was switched on and the final stream consisted of $70 \% \mathrm{H} 2 / \mathrm{Ar}$. Finally, the catalyst was cooled down to $180{ }^{\circ} \mathrm{C}$ and the reaction mixture was introduced. An average of four measurements spaced by $15 \mathrm{~min}$ was taken to assure that a stable state of the catalyst performance was reached.

\section{Results and discussion}




\subsection{Structural and surface characterisation of ZnO supports}

The hydrothermally prepared $\mathrm{ZnO}$ supports showed significantly higher values of BET surface area in comparison to $\mathrm{ZnO}$ COM. The BET surface area results are gathered in Table 1. Within in- house made samples, higher surface areas were obtained for $\mathrm{ZnO}$ supports calcined in oxidative atmospheres. Larger BET surface area after calcination in air/O2 than in $\mathrm{N}_{2}$ were previously observed in case of other oxides [28].

The difference in the surface area obtained with different calcination atmospheres can be linked to the changes in mechanism of thermal decomposition of the precursor with the surrounding atmosphere, where the presence of oxygen increases the formation of highly porous structures due to additional burn out of the material.

The representative XRD patterns of the precursor and $\mathrm{ZnO}$ supports studied are shown in Fig. 1. The XRD peaks of the solid samples before calcination were characteristic of $\mathrm{Zn} 4(\mathrm{CO}) 3(\mathrm{OH}) 6 \mathrm{H} 2 \mathrm{O}$ (JCPDS Card No.11-0287). After calcination, the diffraction peaks in the pattern (see Fig. 1) were indexed to the hexagonal (wurtzite) $\mathrm{ZnO}$ phase (Joint Committee on Power Diffraction Standards card 36-1451). The diffraction peaks at 20 of $31.5^{\circ}, 34.2^{\circ}, 36.0^{\circ}, 47.3^{\circ}, 56.4^{\circ}, 62.6^{\circ}$, $65.6^{\circ}, 67.7^{\circ}, 68.8^{\circ}$ were ascribed to the diffractions from the following $\mathrm{ZnO}$

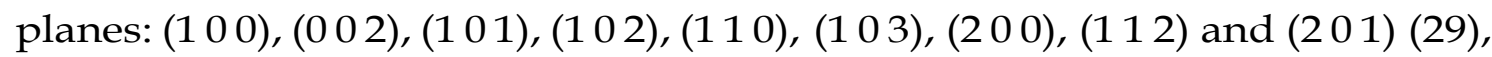
respectively.

It is noted that the XRD patterns for all of the synthesized $\mathrm{ZnO}$ supports closely resembled that of bulk $\mathrm{ZnO}(\mathrm{Zn} C O M)$, regardless the type of gas used during calcination step. However, a typical diffraction peak broadening related to the actual size of the crystallites in a direction normal to the diffracting plane was observed in case of the hydrothermally prepared $\mathrm{ZnO}$ supports. This broadening together with -a small shift towards higher 20 values can be a result of the difference in shape of these crystallites as compared to the $\mathrm{ZnO}$ COM [25].

The reactions of Bronsted acids such as methanol are structurally dependent reactions [30] and more active $\mathrm{PdZn}$ catalysts were previously obtained when $\mathrm{PdZn}$ was supported on $\mathrm{ZnO}$ with (0 0 2) polar facets exposed [31]. With regards to these findings, the anisotropy of the $\mathrm{ZnO}$ supports studied in the present work was compared using the relative ratio of intensity of XRD diffraction peaks of non-polar to polar facet (100)/(002), according to the method proposed by Tsang et al. [32]. Thus, a lower relative ratio of $\left(\begin{array}{lll}1 & 0 & 0\end{array}\right) /\left(\begin{array}{lll}0 & 0 & 2\end{array}\right)$ suggests higher exposure of polar planes, whereas a higher ratio of $\left(\begin{array}{lll}1 & 0 & 0\end{array}\right) /\left(\begin{array}{lll}0 & 0 & 2\end{array}\right)$ suggests growing of the crystal along the c-axis $\left[\begin{array}{llll}0 & 0 & 0 & 1\end{array}\right]$ direction and a high proportion of non-polar 
facets. The obtained (1 00 )/ ( $\left.\begin{array}{lll}0 & 0 & 2\end{array}\right)$ XRD ratios for $\mathrm{ZnO}$ supports are compared in Table 1. As it can be seen from these results, the ratio of relative peak intensities of the studied supports was in the range of 1.13-1.59. It is noted that this is rather small variation, which indicates only small differences in the amount of exposed polar facets among these $\mathrm{ZnO}$ supports. As a matter of fact, the aspect ratio of these $\mathrm{ZnO}$ supports is very similar. The ratio $\left(\begin{array}{lll}1 & 0 & 0\end{array}\right) /\left(\begin{array}{lll}0 & 0 & 2\end{array}\right)$ obtained for commercial $\mathrm{ZnO}$ was 1.2 which agrees well with the reported values [32]. Thus, the lowest exposure of polar facets was obtained in the samples calcined in oxidative atmospheres, as it can be seen in Table 1 . The representative HRTEM images of $\mathrm{ZnO} \mathrm{H} 2$ and $\mathrm{ZnO}$ COM are shown in Fig. 2.

The morphology of the obtained $\mathrm{ZnO}$ supports calcined at various atmospheres was additionally examined by SEM and the resulting micrographs are shown in Fig. 3 together with the related particle size distributions. In general, low magnification images of the $\mathrm{ZnO}$ supports, regardless of the calcination atmosphere, showed mostly uniform spherical particles with diameters in the micron range. However, careful examination disclosed that the morphology of $\mathrm{ZnO}$ was strongly affected by the type of gas used during calcination step.

A closer look at a single particle showed that the $\mathrm{ZnO} O 2$ support (see Fig. 3A and B) contained mostly round flower-like self-assemblies of thin highly porous nanosheets with a mean diameter of $16.8 \mu \mathrm{m}$. The magnified SEM image of the same sample revealed that the nanosheets were self-assembled leaving large voids between each other. In addition, the structure of the nanosheets contained very disordered multiple pores. Thus, high potential for adsorption of gaseous reactants could be anticipated on these $\mathrm{ZnO}$ supports due to the structure of the composing nanosheets. The coarse structure of these nanosheets can be attributed to a fast water removal from the precursor. Similar nanoflower assemblies of $\mathrm{ZnO}$ were obtained in hydro- thermal synthesis and calcination in air [33]. On the contrary, highly magnified SEM images of ZnO $\mathrm{H} 2$ sample (Fig. 3C and D) revealed that the microspheres in this case were constructed by highly ordered and very short multilayer nanosheets that were closely packed together to form a nanoball-like porous structure. In addition, in $\mathrm{ZnO} H 2$ support, the nanosheets were thicker $(60 \mathrm{~nm}$ 
in width) as compared to nanosheets of $\mathrm{ZnO} O 2$. The mean particle size of $\mathrm{ZnO} \mathrm{H} 2$ (see-Fig. 3F) was $15.1 \mu \mathrm{m}$, which taking into consideration the standard deviation is very similar to the size of the particles of $\mathrm{ZnO}$ O2. The morphology of sample $\mathrm{ZnO}$ $\mathrm{N} 2$ closely resembled that of $\mathrm{ZnO} \mathrm{H} 2$ with a mean particle size of $13.1 \mu \mathrm{m}$. On the other hand, the morphology of $\mathrm{ZnO}$ air strongly resembled that of $\mathrm{ZnO} O$ 2, with a mean particle diameter of $15.7 \mu \mathrm{m}$. Therefore, in general it can be concluded that calcination of zinc carbonate dihydrate precursor in oxidizing atmospheres $(\mathrm{O} 2$, air) results in the nanospheres/nanoflowers assemblies consisting of a flower-like structure. This structure was constructed from highly porous long nanosheets that were joined together incorporating big voids between them. Such morphology resulted in a higher specific surface area. On the other hand, if the calcination was done in a reductive or inert atmosphere $\left(\mathrm{H}_{2}\right.$ or $\left.\mathrm{N}_{2}\right)$ the spherical nanoballs were produced with short and densely packed nanosheets. These $\mathrm{ZnO}$ nanoballs had lower BET surface area than the $\mathrm{ZnO}$ supports calcined in oxidizing atmospheres. On the other hand, the size of $\mathrm{ZnO}$ particles obtained by hydrothermal method was very similar, regardless of the calcination atmosphere used. In comparison, $\mathrm{ZnO}$ COM had faceted crystallites that had prevalent morphology of nanorods with approximate dimensions of $80-100 \mathrm{~nm}$ in length and $20 \mathrm{~nm}$ in width (results not shown) and a very low BET sur- face area (listed in Table 1). Thus, in spite of the similar aspect ratio and polarity, the morphologies of the studied $\mathrm{ZnO}$ supports significantly differed from each other. Noteworthy, EDX analysis of the synthesized $\mathrm{ZnO}$ supports and $\mathrm{ZnO} \mathrm{COM}$ agreed well with the XRD results and showed neat $\mathrm{ZnO}$ phases without any impurities.

\subsection{Physicochemical characterization of PdZn/ZnO catalysts}

It was considered of interest to study the possible influence of the morphology of $\mathrm{ZnO}$ support on the onset temperature of $\mathrm{PdZn}$ alloy formation. Thus, the reduction of selected samples was followed by on-line XRD measurements in the temperature range $\left(30-400{ }^{\circ} \mathrm{C}\right)$ and the formation of $\mathrm{PdZn}$ alloy was confirmed in all cases, regardless of the type of $\mathrm{ZnO}$ support present. The representative XRD pattern of $\mathrm{PdZn} / \mathrm{ZnO}$ COM is shown in Fig. 4. In all studied supports, only a very broad peak in the region of $20=40.2^{\circ}$ belonging to $\operatorname{Pd}^{0}$ was observed up to $250{ }^{\circ} \mathrm{C}$, which indicates a small particle size. However, this diffraction peak clearly disappears at higher reduction temperatures. It is thus possible that the amount of remaining $\mathrm{Pd}^{0}$ is below detection limit of the XRD technique, or that the formation of PdZn alloy was completed. As evidenced in Fig. 4, the beginning of alloy formation took place at around $300{ }^{\circ} \mathrm{C}$, which was accompanied by the appearance of the diffraction peaks at $20=41^{\circ}$ and $43.9^{\circ}$ that are close to the values ascribed to PdZn alloy [34]. Upon further heating, the 
crystallinity and particle size of PdZn alloy increased, which was represented by narrowing of these peaks. Similar patterns were obtained for the samples supported on $\mathrm{ZnO}$ calcined in $\mathrm{H} 2, \mathrm{O} 2$, air and N2. Based on these results, $400{ }^{\circ} \mathrm{C}$ was selected in the present work as an optimum reduction temperature. Overall it was concluded that the onset of PdZn alloy formation was not affected by the morphology of the $\mathrm{ZnO}$ support. Lattice fringes of $0.28 \mathrm{~nm}$ were measured from HRTEM micro- graphs for $\mathrm{ZnO} \mathrm{O} 2, \mathrm{ZnO} \mathrm{H}_{2}$ and $\mathrm{ZnO} \mathrm{COM}$ which can be attributed to the exposure of a $\mathrm{ZnO}$ non-polar (llll $\left.\begin{array}{lll}1 & 0\end{array}\right)$ plane [29] which is in agreement with the XRD findings. The formation of PdZn alloy under reduction atmosphere in all of the samples was also further supported by the lattice spacing measurements from HRTEM micrographs. A representative HRTEM image of PdZn ZnOH2 is shown in Fig. 5. As it can be seen in Fig. 5 left, a lattice spacing of $0.22 \mathrm{~nm}$ was obtained for the nanoparticle, which matches the value reported for PdZn alloy (111) [35]. It should be noted, that the lattice fringes of the particles in the range of 3-4 nm were easily obtained, however measuring $\mathrm{d}$ spacings of smaller particles also present in the samples was difficult due to the contrast from the support. Therefore, we have examined more closely selected area of sample PdZn ZnO COM (see Fig. 5, left) that contained the highest average particle size. The image revealed the lattice spacing of the smaller particle (on the left side of Fig. 5) to be $0.23 \mathrm{~nm}$. This result can suggest the presence of $\mathrm{Pd}$ (1 1 1), which possesses lattice spacing slightly higher as compared to that of PdZn alloy in accordance with literature findings [35]. It should be underlined that due to the difference in lattice spacing between PdZn and Pd being not more than 3\% [35], the phase of these small particles in our case could only be conclusively identified as Pd by joined results from HRTEM, TPR, XPS and CO adsorption-DRIFT analysis described later in this work. A representative lower magnification HRTEM image of the same sample together with the corresponding particle size distribution is shown in Fig. 6. Similarly to these results, the HRTEM analysis of the remaining $\mathrm{PdZn} / \mathrm{ZnO}$ catalysts, showed finely dispersed particles with no visible agglomeration, regardless of the calcination atmosphere of $\mathrm{ZnO}$ precursor. The mean diameters obtained from HRTEM images of PdZn supported on hydrothermally synthesized $\mathrm{ZnO}$ were in the range of $2.1 \mathrm{~nm}$ to $3.4 \mathrm{~nm}$, which is significantly lower than the mean diameter of the $\mathrm{PdZn}$ supported on $\mathrm{ZnO}$ COM $(8.8 \mathrm{~nm})$. The sizes of the particles are gathered in Table 2. A clear influence of the morphology of $\mathrm{ZnO}$ support was observed on the crystallization of $\mathrm{PdZn}$ alloy, leading to changes in size of the nanoparticles. In general, smaller particles would be expected on the higher surface area supports, mainly due to higher Pd dispersion and thus longer diffusion distances between neighboring PdZn and decreased sintering of these particles. Nevertheless, no clear trend was observed between the particle size and the surface area of $\mathrm{ZnO}$ support in the studied catalysts. 


\subsection{Methanol steam reforming}

A good catalyst for low temperature MSR should provide high water and methanol conversions to hydrogen and carbon dioxide while minimising occurrence of any side-reactions. The prepared $\mathrm{PdZn}$ alloyed catalysts immobilized on $\mathrm{ZnO}$ calcined under various atmospheres were tested for activity and selectivity in MSR at $180{ }^{\circ} \mathrm{C}$ using an in-house built MSR set-up as described in the Experimental section. The results of the catalytic activity and selectivity expressed by $\mathrm{CO}$ concentration in ppm, are gathered in Table 2 and compared to PdZn alloy supported on $\mathrm{ZnO} C O M$. The BET surface area of $\mathrm{ZnO}$ supports and their polarity can be found in Table 1.

It was rather surprising to find that the catalytic activity was independent from the BET surface area of $\mathrm{ZnO}$ support (compare Table 1 with Table 2), which is in contrast with the literature reports [27]. On the other hand, selectivity to $\mathrm{CO}$ was higher for PdZn catalysts supported on higher surface area $\mathrm{ZnO}$, which were calcined in oxidizing atmosphere. This result can be associated with the apparently lower reducibility of high surface area $\mathrm{ZnO}$ supports. Moreover, the selectivity to $\mathrm{CO}$ was found to be inversely proportional to the activity for the PdZn supported on hydrothermally obtained $\mathrm{ZnO}$ supports (excluding PdZn/ZnO COM). Lower selectivity to $\mathrm{CO}$ was achieved by $\mathrm{PdZn}$ supported on $\mathrm{ZnO}$ with higher exposure of polar facets which is in agreement with the literature [25]. However, no direct trend was established between increased polarity of $\mathrm{ZnO}$ and activity of the $\mathrm{PdZn} / \mathrm{ZnO}$ catalysts, which can be explained by the fact that the range of the polarities studied was very narrow. Additionally, smaller PdZn alloy particles obtained on hydrothermally produced $\mathrm{ZnO}$ displayed better activity per gram of metal than their bigger counterparts supported on $\mathrm{ZnO} \mathrm{COM}$. However, in order to account for the particle size differences between PdZn ZnO H2 and PdZn ZnO COM, the TOF of these samples was compared and the results are gathered in the supplementary material. The amount of active sites was obtained by CO pulse chemisorption taking into consideration the similar amount of PdZn alloy present on the surface of these catalysts, as showed later in the paragraph describing XPS results of the present work. Similar extent of alloy present is essential in case of this comparison, because the presence of $\mathrm{Zn}$ in $\mathrm{Pd}$ decreases the amount of chemisorbed $\mathrm{CO}$ and therefore alters the $\mathrm{Pd}: \mathrm{CO}$ stoichiometry, leading to false number of measured active sites on the catalyst [46]. The TOF of PdZn ZnO H2 was $1.01 \mathrm{~s}^{-1}$ and that of PdZn ZnOCOM was $0.71 \mathrm{~s}^{-1}$, which is in the range of the values reported in the literature for similar systems [16]. These results show that independently of the particle size, the most active catalyst was obtained by supporting $\mathrm{PdZn}$ on $\mathrm{ZnO}$ calcined in reductive atmosphere.

Nevertheless, the greatest differences in performance could be assigned to differences in calcination atmosphere of $\mathrm{ZnO}$ precursor $(\mathrm{H} 2, \mathrm{O} 2, \mathrm{~N} 2$, air). As it can 
be clearly seen in Table 2, the activity of $\mathrm{PdZn} / \mathrm{ZnO}$ catalysts increased with calcination atmosphere from oxidative $\left(\mathrm{O}_{2}\right)$ to reducing $\left(\mathrm{H}_{2}\right)$. It should be underlined that over twofold increase in activity was achieved by supporting $\mathrm{PdZn}$ on $\mathrm{ZnO} \mathrm{H}_{2}$ as compared to $\mathrm{ZnO} \mathrm{O} 2$. Moreover, the selectivity to $\mathrm{CO}$ dropped significantly on the PdZn supported on $\mathrm{ZnO}$ calcined in $\mathrm{N} 2$ and $\mathrm{H}_{2}$ as compared to $\mathrm{PdZn}$ supported on $\mathrm{ZnO}$ calcined in oxidative atmospheres. The decrease in $\mathrm{CO}$ production can be a result of more efficient water activation in these supports, prerequisite for $\mathrm{CO} 2$ selective catalyst in MSR [24]. Overall, the anticipated exceptional increase in activity and selectivity of $\mathrm{PdZn}$ supported on $\mathrm{ZnO}$ calcined in $\mathrm{H} 2$ atmosphere can be associated with the presence of different active sites, mainly oxygen defects on the surface of the support of this catalyst, which alter the adsorption process of substrates and intermediates during low temperature MSR. It is clear that the difference in catalytic performance as a result of the calcination atmosphere of $\mathrm{ZnO}$ showed cannot be attributed to a difference in particle size of the PdZn alloy, as virtually the same particle sizes were obtained in this family of catalysts, regardless of the calcination atmosphere of $\mathrm{ZnO}$. As it was mentioned before, significantly higher size of PdZn particles was noted on the $\mathrm{ZnO} \mathrm{COM}$, which can be attributed to the difference in morphology of the $\mathrm{ZnO}$ support.

Oxygen vacancies present on the surface of an oxide catalyst are important for several catalytic reactions [31]. However, generally the amount of oxygen vacancies is expected to be higher in $\mathrm{ZnO}$ with higher exposure of polar facets, because they are formed to counterbalance the large surface dipole moment [24]. The vacancies can also be created on the non-polar facets of the crystal by treatment in reductive atmosphere, given the right reaction conditions. Much higher conductivity has been previously reported for $\mathrm{ZnO}$ materials calcined in oxygen poor atmospheres, which was attributed to a reversible removal of the oxygen atoms from the $\mathrm{ZnO}$ lattice and releasing free carriers [37]. Thus, it is likely that the outstanding performance of the $\mathrm{PdZn} / \mathrm{ZnO} \mathrm{H} 2$ catalyst in the present work is a result of a higher concentration of oxygen vacancies that are produced according to Eq. (1) [37], even though the exposure of polar facets on this support is not the highest in this work (see Table1)

$2 \mathrm{O}_{i}^{2-} \leftrightharpoons \mathrm{O}_{2}+4 \mathrm{e}^{-}$

These oxygen defects in $\mathrm{ZnO}$ create additional active sites to the ones existing on $\mathrm{PdZn}$ and on $\mathrm{PdZn} / \mathrm{ZnO}$ interface, which are responsible for water adsorption. Such a synergy drastically increases the activity of the catalysts at low temperature MSR. Additionally, the improved water activation increases the selectivity towards $\mathrm{CO} 2$ by decreasing the activity of $\mathrm{PdZn} / \mathrm{ZnO}$ in $\mathrm{MD}$. On the other hand, when the $\mathrm{ZnO}$ precursor is calcined in oxidative atmospheres, the 
surplus oxygen is able to enter the interstitial sites of $\mathrm{ZnO}$ and push the interstitial oxygen atoms back into the lattice, or fill in the existent oxygen vacancies. Thus the amount of $\mathrm{VO}-\mathrm{O} i$ pairs formed decreases. As a result, less available active sites are present on the surface of $\mathrm{ZnO}$ leading to poorer catalytic performance. Noteworthy, further evidence had to be obtained to support this speculation.

\subsection{XPS study of oxygen vacancies in $\mathrm{ZnO}$ supports}

XPS is a very useful technique to investigate the chemical and electronic properties of the heterogeneous catalysts. Particularly, the presence of defects in the structure of $\mathrm{ZnO}$ can cause changes in chemical bonding resulting -in the shifts of binding energy (BE) of the elements in XPS [36]. Thus, the XPS spectra of Pd 3d, Zn 2p, O 1s and C 1s were recorded for selected catalysts and a representative $\mathrm{ZnO} \mathrm{H} 2$ support. A general XPS survey spectra of all of the catalyst samples showed $\mathrm{Pd}, \mathrm{Zn}, \mathrm{C}$ and $\mathrm{O}$ throughout the experiments. With the goal to investigate the abundance of the oxygen vacancies on thePdZnsupported on various $\mathrm{ZnO}$ supports, the electronic state of the O 1s XPS peak was firstly analysed in higher resolution. A resulting comparison of XPS spectra of oxygen 1s region of the $\mathrm{PdZn} / \mathrm{ZnOH} 2$ and $\mathrm{PdZn} / \mathrm{ZnOO} 2$ is shown in Fig. 7. In all cases studied, the obtained O1s asymmetric peak was coherently fitted with three components in agreement with previously reported studies [38]. Accordingly, the oxygen species on the lowest side of the $\mathrm{O} 1$ s spectrum labelled as Oa can be attributed to $\mathrm{Zn}-\mathrm{O}$ bonds of highly crystalline $\mathrm{ZnO}$. The component with the medium BE (labelled $\mathrm{Ob}$ ) can be assigned to $\mathrm{O}^{2-}$ ions in oxygen deficient areas of the $\mathrm{ZnO}$ lattice. The changes in intensity of this component mirror the variation in the concentration of oxygen vacancies in $\mathrm{ZnO}$ support. In addition, the highest $\mathrm{BE}$ peak labelled Oc is associated with adsorbed $\mathrm{OH}$ groups on the surface of $\mathrm{ZnO}$. These groups most likely originate from dissociation of adsorbed water on $\mathrm{ZnO}$, which was produced during reduction of $\mathrm{PdO}$ [39].

The $\mathrm{BE}$ and composition of $\mathrm{O} 1$ s spectra of the representative catalysts and $\mathrm{ZnO} \mathrm{H} 2$ support are gathered in Table 3 . As indicated by the results, the highest amount of vacancies $(\mathrm{Ob})$ was found in $\mathrm{PdZn} \mathrm{ZnO} \mathrm{H} 2$. Over $52 \%$ of the total oxygen species present on the surface of this catalyst was associated with oxygen defects. On the other hand, the lowest amount of oxygen vacancies w' as found in PdZn ZnO COM. Moreover, the PdZn supported on ZnO COM had the highest relative concentration of stoichiometric oxygen (Oa) which agrees well with the XRD result (see Fig. 1), showing that $\mathrm{ZnO} \mathrm{COM}$ had a more crystalline nature than the hydrothermally produced counterparts. In addition, a small shift towards lower values of the BE of oxygen can be noted in case of the most active catalyst as compared to other samples (see Table 3). This can suggest that the electrons are easier to be excited in $\mathrm{ZnO} \mathrm{H} 2$ due to the significantly higher mobility of interstitial charge 
associated with oxygen vacancies. A similar shift of BE of $\mathrm{O}$ 1s was previously reported for $\mathrm{Cu}$ supported on polar $\mathrm{ZnO}$ and was linked to the presence of defects in the ZnO support [21]. Further, as shown in Table 3, the composition of $\mathrm{O} 1$ s peak in $\mathrm{ZnO} \mathrm{H} 2$ did not change significantly upon addition of $\mathrm{Pd}$ and subsequent PdZn alloy for- mation via reduction in $\mathrm{H} 2$. However, a shift of $\mathrm{BE}$ towards higher values was observed in $\mathrm{PdZn} \mathrm{ZnO} \mathrm{H} 2$ as compared to pure support $\mathrm{ZnO} \mathrm{H} 2$ (Table 3), which can be attributed to the electronic inter- action between PdZn and support. The electronic synergy leads to a lower charge concentration and thus a higher oxidation state of oxygen.

With regards to the chemical state of $\mathrm{Zn}$ in PdZn/ZnO catalysts, the XPS spectra of $\mathrm{Zn} 2 \mathrm{p}$ and Auger Zn LMM peaks were also analysed. The representative XPS spectra of $\mathrm{Zn} 2 \mathrm{p} 3 / 2$ of PdZn $\mathrm{ZnO} C O M$ is shown in Fig. 8. The obtained asymmetric $\mathrm{Zn}$ peak could be fitted with two components. Thus, two Zn species coexisted in all of the analyzed catalysts. The lower binding energy was assigned to metallic Zn and the higher BE was assigned to oxidized Zn $[40,41]$. Similar XPS spectra were obtained for the other studied catalysts.

Different amount of oxygen vacancies in $\mathrm{ZnO}$ supports was also confirmed by studying the Auger line of Zn LMM. The BE of Auger Zn LMM is generally more sensitive to the chemical environment [38]. As shown in Fig. 9, there is a positive shift of BE in the presence of an alloy, which is slightly higher in case of the most active $\mathrm{PdZn} / \mathrm{ZnO} \mathrm{H} 2$ sample. The shift of $\mathrm{Zn}$ LMM peaks from low BE to higher values in the presence of the PdZn alloy was caused by the decreased negative charge on $\mathrm{Zn}$. This can be attributed to a synergy between support and PdZn particles in which the electrons from $\mathrm{Zn}$ interact with the positively charged oxygen vacancies unquestionably present on the interface in the $\mathrm{PdZn} / \mathrm{ZnO} \mathrm{H}_{2}$ sample.

The influence of the calcination atmosphere of $\mathrm{ZnO}$ on the chemical and electronic state of Pd species in PdZn/ZnO catalyst was analysed in detail. It was expected that the small local variation of the electronic charge concentration in the $\mathrm{ZnO}$ supports would influence the $\mathrm{BE}$ of $\mathrm{Pd}$ in the resulting $\mathrm{PdZn} / \mathrm{ZnO}$ catalysts. In our study, careful fitting of the obtained XPS signal of Pd $3 d$ in case of all of the catalysts studied here showed similarly the coexistence of three different $\mathrm{Pd}$ species. For example, a representative Pd 3d XPS spectrum of $\mathrm{PdZn} / \mathrm{ZnO} \mathrm{H} 2$ catalyst is shown in Fig. 10. The Pd $3 d$ region presented a doublet of $\mathrm{Pd} 3 \mathrm{~d} 5 / 2$ and $\mathrm{Pd} 3 \mathrm{~d} 3 / 2$ at 335.04 and $340.35 \mathrm{eV}$, which was assigned to $\mathrm{Pd}(0)$ species. Another doublet positioned at 335.93 and $341.29 \mathrm{eV}$ can be assigned to $\mathrm{Pd}$ in $\mathrm{PdZn}$ alloy. With accordance to the literature, the bimetallic bonding with $\mathrm{Zn}$ produces positive BE shift in the core levels and valence $d$ band of the group 10 metals [42]. The positive shift is connected with the reduction of electron population and subsequent shift of the valence $d$ orbital. The remaining third doublet at 336.6 and

$342.4 \mathrm{eV}$ would be attributed to oxidized Pd. The presence of oxidized Pd could 
be expected due to the fact that Pd easily reacts with oxygen from air at ambient conditions and the samples were not pre-reduced in situ before the XPSexperiment. The XPS assignment agrees well with the values reported in the literature $[17,43]$. The existence of $\mathrm{Pd}$ in the metallic state can be the result of not complete alloy formation, or the decomposition of PdZn alloy upon air exposure to $\mathrm{Pd}$ and $\mathrm{Zn}$ [43]. Additionally, the presence of separately existing metallic Pd particles on XPS spectra agrees well with our results from HRTEM image analysis of lattice spacing of single particles.

For comparison, the binding energies obtained for $\mathrm{PdZn} / \mathrm{ZnO} \mathrm{COM}$, $\mathrm{PdZn} / \mathrm{ZnO}$ air, PdZn/ZnO H2, PdZn-ZnO O2 are listed in Table 4. As it can be seen in this table, the XPS surface analysis showed that the surface of the investigated catalysts was composed of PdZn alloyed particles as well as separately existing $\mathrm{Pd}$ metallic particles dispersed on the surface of $\mathrm{ZnO}$ support.

The observed positive shift of binding energy (BE) of $\mathrm{Pd} 3 \mathrm{~d}$ in $\mathrm{PdZn} / \mathrm{ZnO} \mathrm{H}_{2}$ is the result of the strong synergy between the metal alloy nanoparticles and $\mathrm{ZnO}$ support. The increase of $\mathrm{BE}$ can be explained by the interaction of separately existing $\mathrm{Pd}(0)$ particles with local positively charged oxygen vacancies on $\mathrm{ZnO}$ support, resulting in the charge withdrawal from Pd metal, caus- ing the increase in $\mathrm{BE}$ in the core level of the- metal. In addition, the binding energy of Pd in PdZn alloy is shifted to the highest value in $\mathrm{PdZn} / \mathrm{ZnO}$ $\mathrm{H} 2$ as compared BE of PdZn in other studied catalysts. This shift of BE suggests that the surface of PdZn alloy in the most active catalyst is the richest in $\mathrm{Zn}$ of all the PdZn surfaces of the studied catalysts. Noteworthy, better catalytic performance of $\mathrm{Zn}$ rich PdZn alloys was previously reported in MSR [17,24]. Moreover, the ratio of intensity of the photoelectron peak of $\mathrm{Zn} \mathrm{2p3/2}$ to $\mathrm{Pd}$ $3 \mathrm{~d} 5 / 2$ was calculated, normalised by the appropriate atomic sensitivity factors of $\mathrm{Pd}=4.8$ and $\mathrm{Zn}=4.6$ [44]. As it is listed in Table 4, the most active catalyst $\mathrm{PdZn} / \mathrm{ZnO} \mathrm{H} 2$ as well as the least active PdZn/ZnO COM had the highest total amount of Pd exposed on the surface of the catalyst, whereas PdZn supported on $\mathrm{ZnO}$ calcined in oxidizing atmospheres had relatively less exposure of Pd on the surface. Taking into consideration that $\mathrm{ZnO}$ calcined in $\mathrm{O} 2$ or air had significantly higher BET surface areas (see Table 1), it is most likely that Pd in these catalysts is encapsulated in the pores of $\mathrm{ZnO}$ supports. The composition of $\mathrm{Pd} 3 \mathrm{~d}$ based on the relative intensity of Pd 3d signals was calculated and it is shown in Table 4 . When comparing the catalysts activity results (see Table 2) with the catalyst compositions taken from XPS results, a clear correlation can be established between the selectivity to $\mathrm{CO} 2$ of $\mathrm{PdZn} / \mathrm{ZnO}$ catalysts and the extent of alloy formation. The selectivity to MSR increased proportionally to the amount of PdZn alloy formed. Interestingly, PdZn/ZnO COM with a high alloy extent (over 50\%), showed the poorest activity in low temperature-MSR. On the other hand, $\mathrm{PdZn} / \mathrm{ZnO} \mathrm{H}_{2}$ with very similar composition of $\mathrm{Pd} 3 \mathrm{~d}$ peak showed the best performance regarding selectivity and activity in this reaction. Therefore, it can be concluded 
that no direct correlation could be found between the extent of alloy formation and activity of the catalyst in low temperature -MSR. On the other hand, lower activity of $\mathrm{PdZn} \mathrm{ZnO} \mathrm{COM}$ generally could be associated with a much higher size of PdZn alloy. However it was previously reported that the increase in PdZn particle had no adverse effect on the activity of the catalyst in MSR [34]. Thus, the lower activity can be associated with the negative influence of the type of active sites present on the surface of $\mathrm{ZnO} C O M$ support.

\subsection{Study of the metal-support interaction by TPR experiments}

In order to explore in more detail the interaction between metal species and $\mathrm{ZnO}$ supports calcined in various atmospheres, TPR experiments were conducted. The XPS study showed clearly that the electronic state of $\mathrm{ZnO}$ support is strongly affected by the type of gas used during its calcination. Thus, it could be anticipated that the reduction characteristics of these catalysts would also vary with the type of $\mathrm{ZnO}$ support or more specifically with the calcination atmosphere of the support.

The H2-TPR profiles of the studied catalysts are displayed in Fig. 11. It should be noted that no hydrogen consumption or desorption was recorded on the pure $\mathrm{ZnO} \mathrm{H} 2$ support. This clearly indicates that in the absence of $\mathrm{Pd}, \mathrm{ZnO} \mathrm{H} 2$ cannot be reduced below $600{ }^{\circ} \mathrm{C}$. Surprisingly, the negative peak at low temperature commonly assigned to decomposition of $\mathrm{PdHx}$ was not observed in our experiments. This low temperature peak indicates the presence of metallic $\mathrm{Pd}$ in the samples [34]. The presence of Pd metal was evident in the XPS results and HRTEM, so the absence of this TPR peak was rather surprising. Nevertheless, this can be explained by the fact that the hydride could be decomposed once it was formed; therefore observation of the TPR decomposition peakcould be masked by a major and positive peak due to the reduction of $\mathrm{PdO}$ as it was reported in other studies [39]. It was noted that the reduction of all of the $\mathrm{PdZn} / \mathrm{ZnO}$ catalysts started at a similar low temperature range of $51-70^{\circ} \mathrm{C}$. These TPR peaks were undoubtedly attributed to the reduction of $\mathrm{PdO}[45,46]$. It should be mentioned that these reduction temperatures are generally lower than the values reported in the literature for similar catalytic systems [46,47]. This indicates that the palladium oxide in this work was present in the form of a passive thin surface layer on the well dispersed Pd particles. Interestingly, there are two overlapping peaks observed in the case of catalysts calcined in N2, and air (the first around 60

${ }^{\circ} \mathrm{C}$ and the other around $70{ }^{\circ} \mathrm{C}$ ), but importantly, in the case of the former the low temperature peak is more prominent. On the other hand, in PdZn/ZnO air, a slightly higher intensity was recorded for the higher temperature peak. The difference in intensity of these peaks can be the result of the influence of the presence of $\mathrm{O}_{2}$ during calcination of $\mathrm{ZnO}$ air, which is able to create special active 
sites on the support. This assumption was confirmed by the TPR profile of $\mathrm{PdZn} / \mathrm{ZnO}$ O2, where one peak is observed at around the same temperature of $72{ }^{\circ} \mathrm{C}$ with a small shoulder at lower temperatures. The presence of two peaks in the TPR profile suggests the co- existence of two different $\mathrm{Pd}^{2+}$ species with different environment and type of interaction with $\mathrm{ZnO}$ support. Thus, the lower temperature peak was attributed to the interface-boundary oxygen atoms on Pd which are in close vicinity to the oxygen vacancies. The reduction of $\mathrm{PdO}$ in these areas is promoted by strong metal-support interaction and it is influenced by the increased mobility of lattice oxygen. Thus, this peak is more intense in PdZn supported on $\mathrm{ZnO}$ N2 than in $\mathrm{PdZn} \mathrm{ZnO}$ air. Similar observations were made in the TPR studies of $\mathrm{Cu}$ catalysts [47] and Ce doped with $\mathrm{CuO}[48,49]$. With a strong agreement to the above conclusion, the most active catalyst ( $\mathrm{PdZn} / \mathrm{ZnO} \mathrm{H} 2$ ) shows a broad peak at a lower temperature $\left(58^{\circ} \mathrm{C}\right)$, suggesting the presence of the active sites in the close proximity to the defected $\mathrm{ZnO}$ sites. In addition, as it could be anticipated from other results, PdZn COM showed a single very sharp peak at a higher temperature $\left(68^{\circ} \mathrm{C}\right)$, indicating one type of $\mathrm{PdO}$ present on this catalyst, possibly supported on stoichiometric $\mathrm{ZnO}$. In addition, there is a very broad peak visible in temperatures above $250{ }^{\circ} \mathrm{C}$ in all of catalysts studied, which represents a continuous PdZn alloy formation [4]. The dissociation of molecular hydrogen on the surface of $\mathrm{Pd}$ metal provides very active atomic hydrogen which reduces $\mathrm{ZnO}$ by abstracting $\mathrm{O}^{2}-$ from its surface. Overall, the presence of oxygen vacancies is apparent in TPR results, leading to a significant decrease in the reduction temperature of the neighboring PdO. Noteworthy, a decrease in the reduction temperature of the metal oxide supported on redox-active oxide such as $\mathrm{ZnO}$ is a reliable sign of the established strong metal support interaction (SMSI) [26]. It is clear that the calcination atmosphere of $\mathrm{ZnO}$ influences the reduction profile of the $\mathrm{PdZn} / \mathrm{ZnO}$ catalysts. In summary, the TPR results agreed well with the XPS findings and also points at existence of metallic Pd particles along with $\mathrm{PdZn}$ alloyed particles on the surface of $\mathrm{ZnO}$.

\subsection{DRIFT study of CO adsorption on PdZn/ZnO catalysts}

CO-adsorption-DRIFT analysis presents a unique tool to probe the chemical nature of the adsorption sites on the catalyst surface. This is because the bonding of $\mathrm{CO}$ to the metal is sensitive to the oxidation and coordination of the catalytically active sites. Thus, the position of the $\mathrm{CO}$ adsorption band on a given metal depends on the oxidation state of a metal site, nature of exposed faces and the particle size [50]. It is clear that the existence of different active sites/ensembles on $\mathrm{PdZn} / \mathrm{ZnO}$ catalyst may lead to pronounced differences in its performance in low temperature-MSR. Thus, DRIFT spectra using CO as a probe molecule were 
recorded at room temperature in the region of $2200-1900 \mathrm{~cm}^{-1}$ for representative $\mathrm{PdZn} / \mathrm{ZnO}$ catalysts. The resulting DRIFT spectra are presented in Fig. 12. The spectra were recorded in the increasing $\mathrm{CO}$ exposure time from spectra 1 freshly reduced catalyst to spectra to spectra three, four-fully saturated sample.

All the DRIFT results showed the coordination bands of $\mathrm{CO}$ in two regions. CO adsorbed in bridging mode (1981-1960 $\mathrm{cm}^{-1}$ ) on the $\mathrm{Pd}(0)$ and $\mathrm{CO}$ adsorption on the steps and edges of rows of Pd in PdZn in linear (a-top) mode (2093-2010 $\mathrm{cm}^{-1}$ ) [51] [52]. The modes of adsorption are schematically shown in Fig. 12.A. The bands with a wavenumber higher than $2150 \mathrm{~cm}^{-1}$ can be assigned to $\mathrm{CO}$ in gas phase [52]. As it can be seen from this study, the type of $\mathrm{ZnO}$ substrate affects the vibrational frequency of adsorbed $\mathrm{CO}$. The presence of the bridging mode is the result of ensemble of neighboring Pd atoms on the surface of all the catalysts. This confirms the previous results from the catalysts composition obtained in TPR, XPS and HRTEM studies. The CO adsorbs mostly in bridging mode on $\mathrm{PdZn} / \mathrm{ZnO} \mathrm{N} 2$ and $\mathrm{PdZn} / \mathrm{ZnO}$ O2. This finding agrees well with the XPS results that showed lower alloy formation in $\mathrm{PdZn} / \mathrm{ZnO} \mathrm{O}_{2}$ sample as compared with $\mathrm{PdZn/ZnO} \mathrm{COM.} \mathrm{Thus,} \mathrm{due} \mathrm{to} \mathrm{higher} \mathrm{alloy} \mathrm{extent} \mathrm{present} \mathrm{in} \mathrm{PdZn/ZnO} \mathrm{COM,} \mathrm{CO}$ adsorbed mainly in linear mode on this sample (see Fig. 12 D). Moreover, higher concentration of $\mathrm{CO}$ linearly bonded to $\mathrm{Pd}$ was found on the samples with higher concentration of $\mathrm{Zn}$ on the surface [52]. Taking into consideration the size of the $\mathrm{PdZn}$ nanoparticles, it can be concluded that $\mathrm{CO}$ adsorbs mostly in bridging mode on the smaller PdZn particles. On the most active catalyst, $\mathrm{PdZn} / \mathrm{ZnOH} 2$ there is also two adsorption modes present. Careful analysis of the wavenumbers revealed that there is a blueshift of bridging mode on the $\mathrm{PdZn} / \mathrm{ZnO} \mathrm{H} 2\left(1975.58 \mathrm{~cm}^{-1}\right)$ and linear mode $\left(2075.1 \mathrm{~cm}^{-1}\right)$ as compared to the bridging mode $\left(1979.1 \mathrm{~cm}^{-1}\right)$ and linear mode $\left(2087 \mathrm{~cm}^{-1}\right)$ on $\mathrm{PdZn} / \mathrm{ZnO}$ O2 or bridging $\left(1981.1 \mathrm{~cm}^{-1}\right)$ and linear $\left(2100 \mathrm{~cm}^{-1}\right)$ on PdZn/ZnO N2. This shift of wavenumber to lower values can be ascribed to the electronic interaction between $\mathrm{Pd}$ and $\mathrm{ZnO}$ support. The presence of free electrons from oxygen vacancies in $\mathrm{ZnO}$ increases the charge of $\mathrm{Pd}$. In general, higher elec- tron density of metal increases the back-donation to $2 T T^{*}$ orbitals of adsorbed $\mathrm{CO}$ which in turn makes the adsorption weaker and shifted to lower frequencies [36]. The presence of free electrons associated with the vacancies on $\mathrm{ZnO}$ support in $\mathrm{PdZn} / \mathrm{ZnO} \mathrm{H} 2$ sample was previously confirmed by TPR and XPS results in the present work.

Moreover, limited stability of the PdZn surface alloy in all of the samples was observed with a prolonged exposure to $\mathrm{CO}$ atmosphere. As it can be seen in Fig. 12 , there was a redshift observed with increasing time in $\mathrm{CO}$ atmosphere. The saturated spectra numbers three and four on each of the samples in this figure 
closely resembled that of $\mathrm{CO}$ adsorbed on $\mathrm{Pd}$ metal. This result strongly indicates that there are some homogenous structural changes taking place on the - surface of the studied catalysts. With increasing time, new surface sites are created on these catalysts which are probably $\mathrm{Pd}$ rich. Since interaction of $\mathrm{CO}$ with Pd sites is much stronger than its interaction with Zn containing sites [36] it can be assumed that as a result of the strong interaction with $\mathrm{CO}$, the Pd atoms in PdZn bulk alloy segregate to the surface. Similar observations were described by other authors [53], however in our case changes of observed intensity of the bands were only noted in case of $\mathrm{PdZn} / \mathrm{ZnO} \mathrm{H} 2$ sample. The most active catalyst showed redshift of the frequencies accompanied by increased intensity of bridging mode with exposure time. In this case, the surface reconstruction step might be affected by the presence of free electrons on the sur- face of $\mathrm{ZnO}$ support, which can give rise to the production of new active sites on the surface. Therefore, it is very likely that the PdZn alloys on these supports could be prone to segregation of $\mathrm{Pd}$ to the surface of the catalyst. The results of CO-DRIFT analysis suggested that the stability of these catalysts under methanol steam reforming conditions could be limited. Therefore, the stability of the representative catalyst $\mathrm{PdZn} \mathrm{ZnO} \mathrm{H}_{2}$ was tested under methanol steam reforming conditions for a period of $48 \mathrm{~h}$ and the result is depicted in Supplementary material, Fig. s1. A total drop of conversion of $24 \%$ was recorded, which is slightly higher than the values reported in the literature for the similar system [54]. This very interesting result can be undoubtedly attributed to the restructuring changes of the sur-face of $\mathrm{PdZn} / \mathrm{ZnO}$ catalyst under MSR conditions. The instability of this catalytic system will be studied in more detail in our future work.

\section{Conclusions}

The obtained results clearly identify that strong synergism between active sites present on intermetallic PdZn alloy and active sites present $\mathrm{ZnO}$ support is necessary to obtain excellent catalytic performance of $\mathrm{PdZn} / \mathrm{ZnO}$ systems in methanol steam reforming. The XPS study showed that the composition of the surface of the studied catalysts contained a mixture of $\mathrm{Pd}$ metallic and $\mathrm{PdZn}$ alloyed particles supported on $\mathrm{ZnO}$. It should be noted that the amount of Pd metallic present on the surface of the studied catalysts as calculated from XPS experiments was very similar in case of all the materials studied. Therefore, it can be concluded that the presence of these particles had no adverse effects on the catalysts performance, which agrees well with the literature findings [35]. Indeed, the activity of these monometallic Pd particles is altered by the presence of the $\mathrm{ZnO}$ support, favoring higher production of $\mathrm{CO} 2$ over $\mathrm{CO}$.

The influence of the calcination atmosphere of the $\mathrm{ZnO}$ precursor on the performance of $\mathrm{PdZn} / \mathrm{ZnO}$ catalyst in low temperature MSR was studied in detail and a very active and ultraselective catalyst was obtained by supporting 
$\mathrm{Pd}$ on $\mathrm{ZnO}$ calcined in $\mathrm{H} 2$. The activity of the PdZn catalyst was found to be independent of the extent of the PdZn alloy formed. However, higher selectivities to $\mathrm{CO} 2$ were achieved by the samples showing higher amount of PdZn alloy on the surface as evidenced by XPS results. The extent of alloy formation was found to be influenced by the BET surface area and $\mathrm{ZnO}$ supports with higher BET values displayed lower extent of alloy formation. A direct correlation was found for the first time between the catalytic performance of $\mathrm{PdZn} / \mathrm{ZnO}$ catalysts in low tempera- ture MSR and the calcination atmosphere of the $\mathrm{ZnO}$ support. Thus, the performance of the catalysts increased from $\mathrm{PdZn}$ supported on $\mathrm{ZnO}$ calcined in oxidative atmospheres to $\mathrm{PdZn} / \mathrm{ZnO}$ calcined in nitrogen and was the best in case of $\mathrm{PdZn}$ supported on $\mathrm{ZnO}$ calcined in $\mathrm{H} 2$. The exceptional performance in low temperature MSR of $\mathrm{PdZn} / \mathrm{ZnO} \mathrm{H} 2$ catalyst was attributed to the presence of higher concentration of oxygen vacancies in $\mathrm{ZnO} \mathrm{H}_{2}$, as evidenced by TPR, XPS and CODRIFT studies. The gathered results showed that the activity of $\mathrm{PdZn}$ catalyst is strongly affected by the morphology and crystallinity of the ZnO support which governs the type of specific active sites responsible mainly for water activation. The stronger synergy between $\mathrm{Pd}$ and $\mathrm{ZnO}$ was achieved in the presence of oxy-gen vacancies in $\mathrm{ZnO}$ support, which resulted in the high selectivity towards MSR of the best catalyst. Thus, a clear correlation was dis- covered for the first time between the amount of oxygen defects present on the ZnO support as indicated by XPS, TPR, CO-DRIFT studies and the activity of $\mathrm{PdZn} / \mathrm{ZnO}$ catalysts. Unfortunately, the PdZn alloy in these systems was found to be unstable under pro- longed $\mathrm{CO}$ exposure during DRIFT experiments. The stability test carried out under methanol steam reforming conditions showed a $24 \%$ drop in conversion of the most active catalyst during $48 \mathrm{~h}$ on stream. Thus, it was confirmed that surface reconstruction is likely to take place during the MSR reaction, possibly involving either segregation of $\mathrm{Pd}$ to the surface from the bulk of the PdZn alloy, or other changes in the composition of the PdZn alloy due to reorder- ing under reaction conditions. Further research is currently carried out to understand the mechanism of deactivation of these catalytic systems.

To sum up, it is expected that the presented results would aid in the rational design of more active and selective catalyst for application at even lower temperature $\left(170^{\circ} \mathrm{C}\right)$ for hydrogen production by MSR.

\section{Acknowledgement}

The research leading to these results has received funding from European Union' Seventh Framework Programme (FP7/2007-2013) for the Fuel Cells and Hydrogen Joint Technology Initiative under grant agreement number $303476 \quad 10$ (BeingEnergy). K.Eblagon is grateful for the financial support from FCT 
postdoctoral grant (PTDC/CTM/108454/2008) co-financed by FEDER and POFC and PTDC/EQU-EQU/104217/2008. The work of H.Silva was supported by FCT, grant SFRH/BD/45890/2008. Mr. F. Eblagon and Dr L. Brandão are acknowledged for fruitful discussions of the data. Dr L. Jorda Moret from ITQ-Universidad Politecnica de Valencia is thanked for performing the XRD study of PdZn alloy formation. Authors are also grateful to Dr M. Reinikainen and Dr S. Pekka from VTT Technical Research Centre of Finland for performing TPR mea- surements. Mr. P. Ribeirinha from FEUP is thanked for performing the stability tests and Dr. P.J.F.Harris is acknowledged for performing additional HRTEM characterization.

\section{Appendix A. Supplementary data}

Supplementary data associated with this article can be found, in the online version, at http:/ / dx.doi.org/10.1016/j.apcatb.2014. 02.032.

\section{References}

[1] M.U. Niemann, S.S. Srinivasan, A.R. Phani, A. Kumar, D.Y. Goswami, E.K. Ste- fanakos, J. Nanomater. 2008 (2008) 1-9.

[2] B. Lindström, L.J. Pettersson, P.G. Menon, Appl. Catal. A 234 (2002) 11125.

[3] Y.-H.P. Zhang, J.-H. Xu, J.-J. Zhong, Int. J. Energy. Res. 37 (2013) 769779 .

[4] N. Iwansa, M. Yokoshikawa, W. Nomura, M. Arai, Appl. Catal. A 292 (2005) 215-222.

[5] G.A. Olah, Angew. Chem. Int. Ed. 44 (2005) 2636-2639.

[6] S. Kim, M. Kang, J. Ind. Eng. Chem. 18 (2012) 969-978.

[7] D.R. Palo, Chem. Rev. 107 (2007) 3992-42021.

[8] P. Bichon, M. Asheim, A. Jordal, T. Sperle, M. Fathi, A. Holmen, E.A.

Blekkan, Int. J. Hydrogen Energy 32 (2007) 1799-1805.

[9] J.-P. Shen, C. Song, Catal. Today 77 (2002) 89-98.

[10] C.E. Taylor, B.H. Howard, C.R. Myers, Ind. Eng. Chem. Res. 46 (2007) 8906-8909.

[11] O. Llinich, Y. Liu, C. Castellano, G. Koermer, A. Moini, R. Farrauto, Platinum Met. Rev. 52 (2008) 134-143.

[12] K.M.K. Yu, W. Tong, A. West, K. Cheung, T. Li, G. Smith, Y. Guo, S.C. Tsang, Nat. Commun. 3 (2012) 1-7.

[13] S. Sá, H. Silva, L. Brandão, J.M. Sousa, A. Mendes, Appl. Catal. B 99 (2010) 43-57.

[14] M.-C. Tsai, J.-H. Wang, C.-C. Shen, C.-T. Yeh, J. Catal. 279 (2011) 241245.

[15] Y. Matsumura, H. Ishibe, J. Mol. Catal. A 345 (2011) 44-53. 
[16] N. Iwasa, S. Kudo, H. Takahashi, S. Masuda, N. Takezawa, Catal. Lett. 19 (1993) 211-216.

[17] M. Friedrich, D. Teshner, A. Knop-Gericke, M. Armbruster, J. Catal. 285 (2012) 41-47.

[18] Y. Usami, K. Kagawa, M. Kawazoe, Y. Matsumura, Appl. Catal. A 171 (1998) 123-130.

[19] N. Iwasa, N. Takezawa, Top. Catal. 22 (2003) 215-224.

[20] M. Friedrich, S. Penner, M. Heggen, M. Armbruster, Angew. Chem. Int. Ed. 52 (2013) 4389-4392.

[21] F. Liao, Y. Huang, J. Ge, W. Zheng, K. Tedsree, P. Collier, X. Hong, S.C.

Tsang, Angew. Chem. Int. Ed. 50 (2011) 2162-2165.

[22] E. Jeroro, J.M. Vohs, J. Am. Chem. Soc. 130 (2008) 10199-10207.

[23] H. Lorenz, C. Rameshan, T. Bielz, N. Memmel, W. Stadlmayr, L. Mayr, Q.

Zhao, S. Soisuwan, B. Klötze, Chem. Catal. Chem. 5 (2013) 1273-1285.

[24] J. Strunk, K. Kahler, X. Xia, M. Muhler, Surf. Sci. 603 (2009) 1776-1783.

[25] B. Halevi, S. Lin, A. Roy, H. Zhang, E. Jeroro, J. Vohs, Y. Wang, H. Guo, J.

Phys. Chem. C 117 (2013) 6493-6503.

[26] N. Acerbi, S.C.E. Tsang, G. Jones, S. Golunski, P. Collier, Angew. Chem.

Int. Ed. 52 (2013) 1-6.

[27] G. Xiong, L. Luo, C. Li, X. Yang, Energy Fuels 23 (2009) 1342-1346.

[28] M. Arsalanfar, A.A. Mirzaei, H.R. Bozorgzadeh, J. Nat. Gas Sci. Eng. 6 (2012) 1-13.

[29] M.Y. Ge, H.P. Wu, L. Niu, J.F. Liu, S.Y. Chen, P.Y. Shen, Y.W. Zeng, J. Cryst. Growth 305 (2007) 162-166.

[30] J. Kiss, A. Witt, B. Meyer, D. Marx, J. Chem. Phys. 130 (2009) 184706 184720.

[31] G.R. Li, T. Hu, G.L. Pan, T.Y. Yan, X.P. Gao, H.Y. Zhu, J. Phys. Chem. C 112 (2008) 11859-11864.

[32] A. Mclaren, T. Valdes-Solis, G. Li, S.C. Tsang, J. Am. Chem. Soc. 131 (2009) 12540-12541.

[33] C. Shao, L. Tu, A. Yu, B. Li, X. Zhou, Thin Solid Films 525 (2012) 148-153.

[34] W. Yanhua, Z. Jingchang, X. Hengyong, B. Xuefeng, Chin. J. Catal. 28 (2007) 234-238.

[35] A. Karim, T. Conant, A. Datye, J. Catal. 243 (2006) 420-427.

[36] I. Eswaramoorthi, A.K. Dalai, Int. J. Hydrogen Energy 34 (2009) 25802590.

[37] S. Du, Y. Tian, H. Liu, J. Liu, Y. Chen, J. Am. Ceram. Soc. 89 (2006) 2440 2443.

[38] P.T. Hsieh, Y.C. Chen, K.S. Kao, C.M. Wang, Appl. Phys. A 90 (2008) 317321.

[39] M.L. Cubeiro, J.L.G. Fierro, Appl. Catal. A: Gen. 168 (1998) 307-322.

[40] M. Chen, X. Wang, Y.H. Yu, Z.L. Pei, X.D. Bai, C. Sun, R.F. Huang, L.S. 
Wen, Appl. Surf. Sci. (2000) 134-140.

A. M. Leonarda, E. Moretti, L. Storaro, P. Patrono, F. Pinari, E. RodriguezCastellon, Jimenez-Lopez, G. Busca, E. Finocchio, T. Montanari, R. Frattini, Appl. Catal. 312 (2006) 220-228.

[41] J.A. Rodriguez, M. Kuhn, J. Phys. Chem. 100 (1996) 381-389.

[42] V. Engels, D.A. Jefferson, F. Benaskar, P.C. Thune, A. Berenguer-

Murcia, B.F.G. Johnson, A.E.H. Wheatley, Nanot 22 (2011) 205701-205721.

[43] http://www.cem.msu.edu [Online].

[44] P. Pfeifer, K. Schubert, M.A. Liauw, G. Emig, Appl. Catal., A 270 (2004) 165-175.

[45] Y.-H. Chin, R. Dagle, J. Hu, A.C. Dohnalkova, Y. Wang, Catal. Today 77 (2002) 79-88.

[47] L. Yang, G.-D. Lin, H.-B. Zhang, Appl. Catal., A 455 (2013) 137-144.

[48] S. Patel, K.K. Pant, Fuel Process. Technol. 88 (2007) 825-832.

[49] A. Aranda, S. Agouram, J.M. López, A.M. Mastral, D.R. Sellick, B. Solsona, S.H. Taylor, T. García, Appl. Catal., B 127 (2012) 77-88.

[50] S. Royer, D. Duprez, Chem. Catal. Chem. 3 (2011) 24-65.

[51] W.Stadlmayr, C. Rameshan, C. Weilach, H. Lorenz, M. Hävecker, R. Blume,

T. Rocha, D. Teschner, A. Knop-Gericke, D. Zemlyanov, S. Penner, R. Schlögl, G. Rupprechter, B. Klötzer, N. Memmel, J. Phys. Chem. C 114 (2010) 1085010856.

[52] L. Bollmann, J.L. Ratts, A.M. Joshi, W.D. Williams, J. Pazmino, Y.V. Joshi, J.T. Miller, J. Catal. 257 (2008) 43-54.

[53] K. Föttinger, Catal. Today 208 (2013) 106-112.

[54] T. Conant, A.M. Karim, V. Lebarbier, Y. Wang, F. Girgsdies, R. Schlögl, A. Datye, J. Catal. 257 (2008) 64-70. 


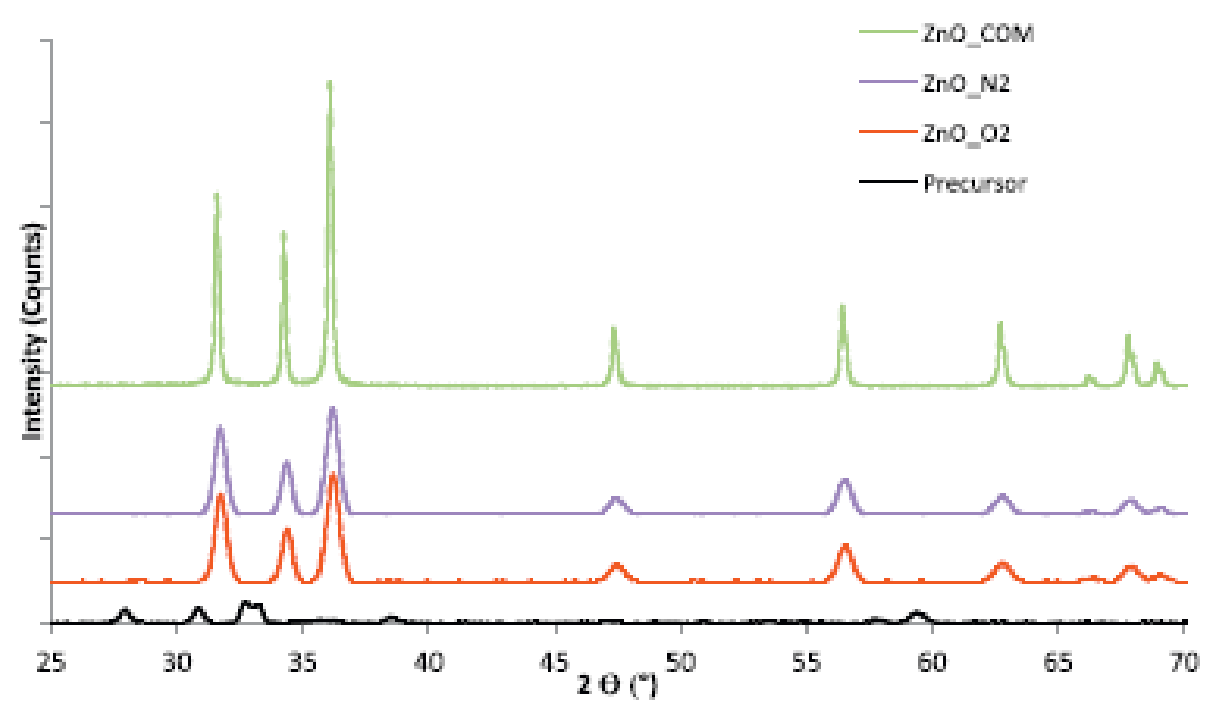

Fig. 1. XRD pattern of $\mathrm{Zn}_{4} \mathrm{CO}_{3}(\mathrm{OH})_{6}-\mathrm{H}_{2} \mathrm{O}$ (precursor), $\mathrm{ZnO}$ calcined in $\mathrm{N}_{2}\left(\mathrm{ZnO}_{2} \mathrm{~N}_{2}\right)$, $\mathrm{ZnO}$ calcined in $\mathrm{O}_{2}\left(\mathrm{ZnO} \mathrm{O}_{2}\right.$ ) and $\mathrm{ZnO}$ commercial (ZnO_COM). 


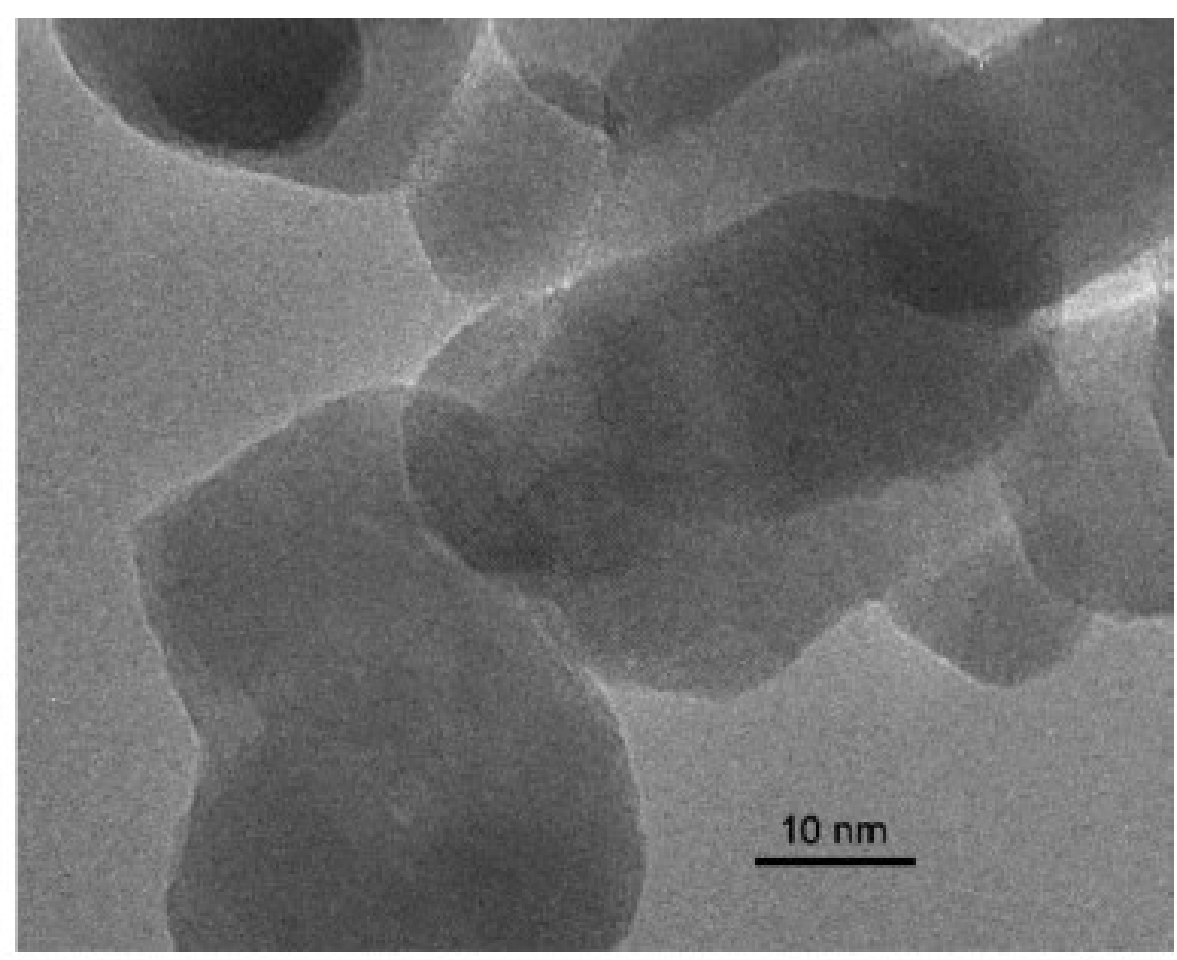

A

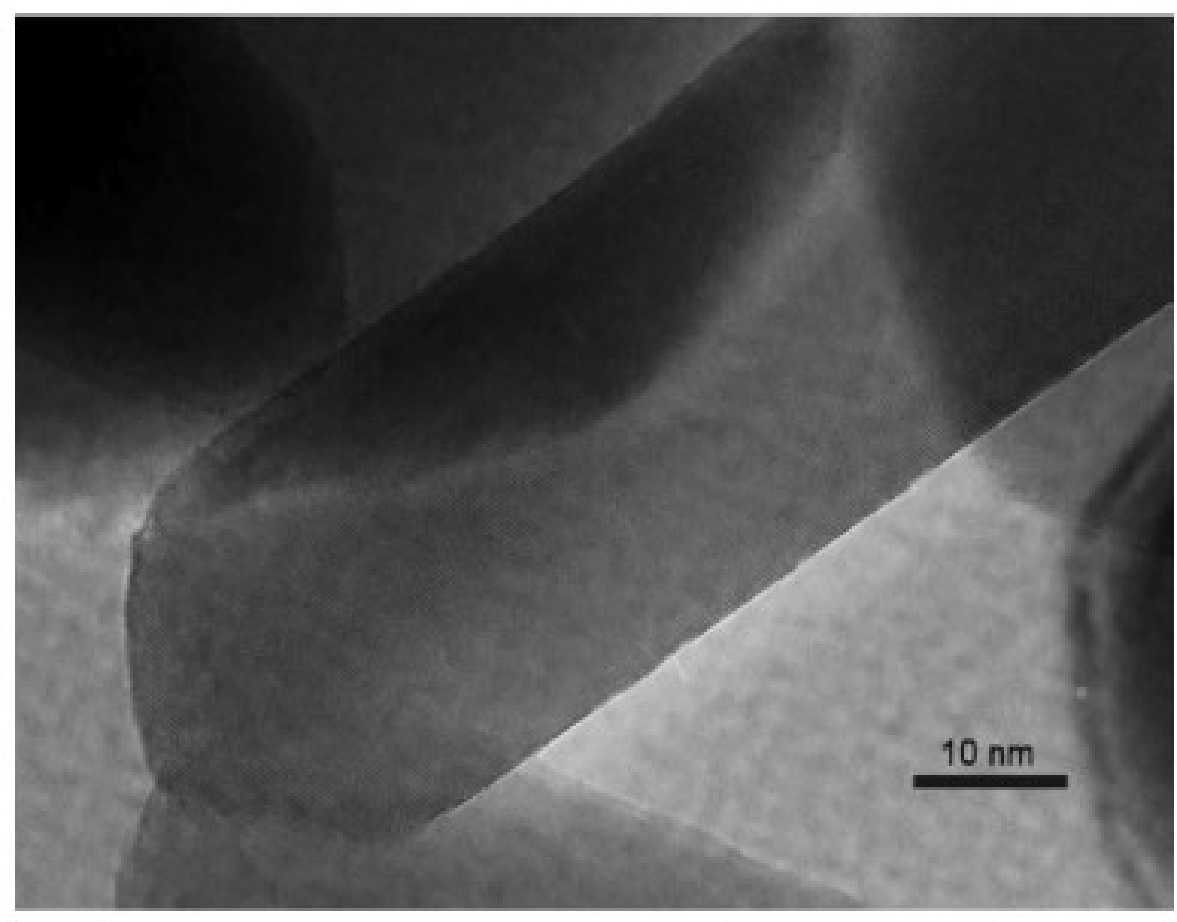

R

Fig. 2. HRTEM micrographs of $\mathrm{A}) \mathrm{ZnO} \mathrm{H}_{2}$ and $\left.\mathrm{B}\right) \mathrm{ZnO}$ _COM. 

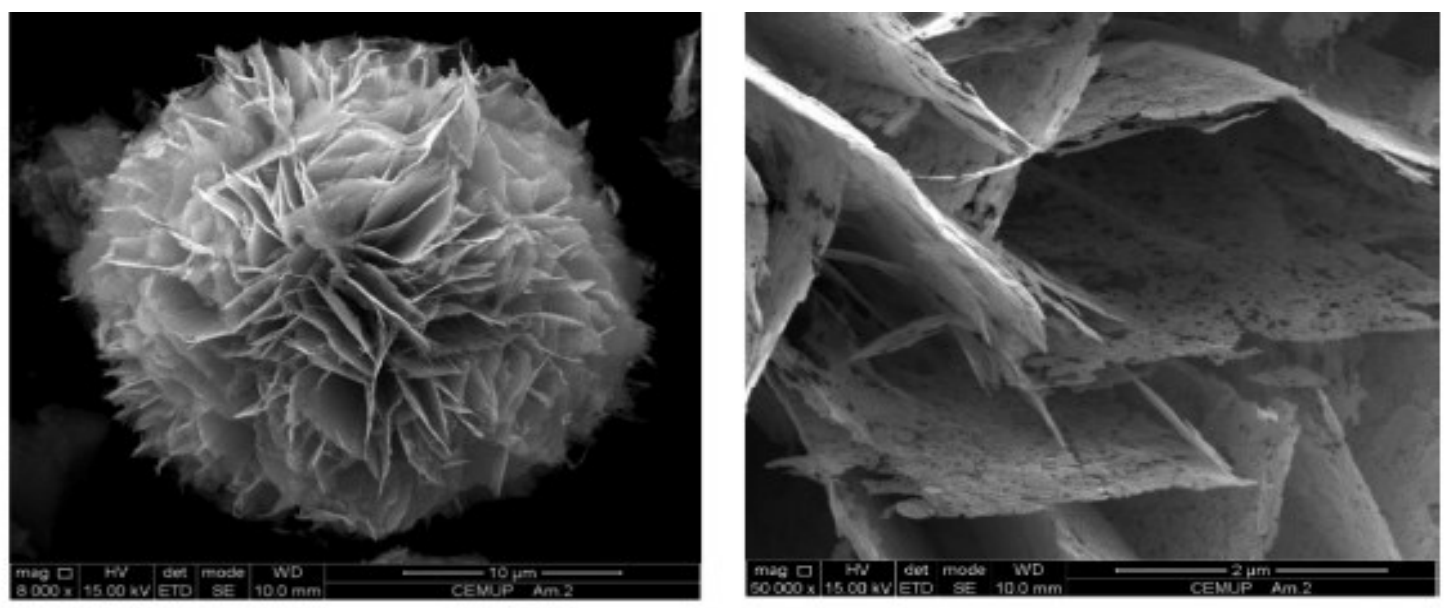

A

B
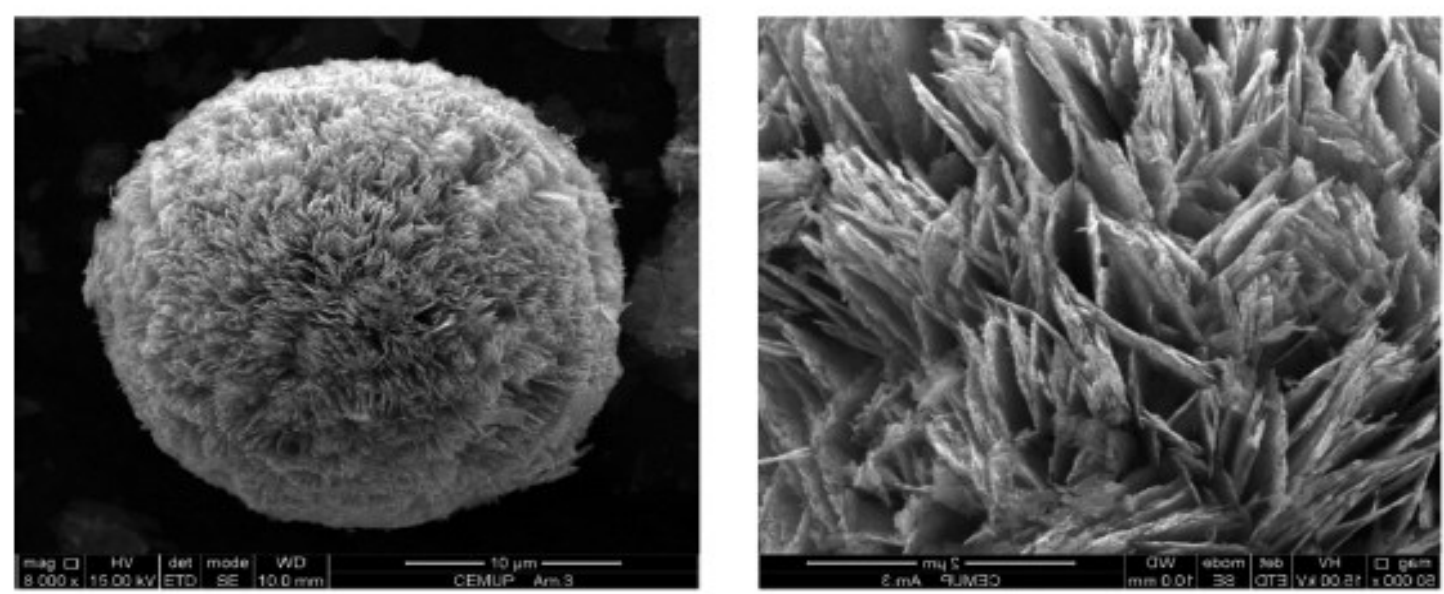

$\mathrm{C}$

D
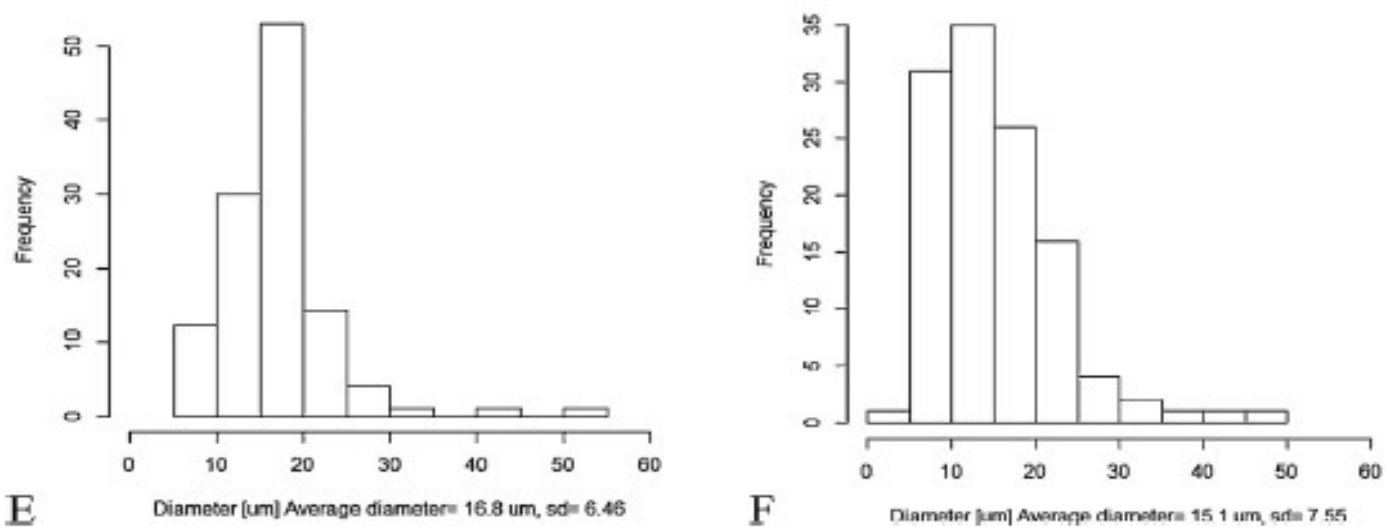

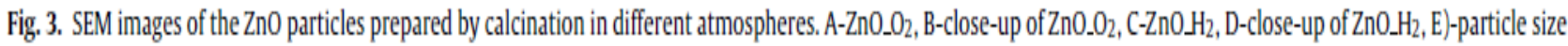
distribution of $\mathrm{Zn} 0 . \mathrm{O}_{2}$, F) particle size distribution of $\mathrm{ZnO}_{-} \mathrm{H}_{2}$. 


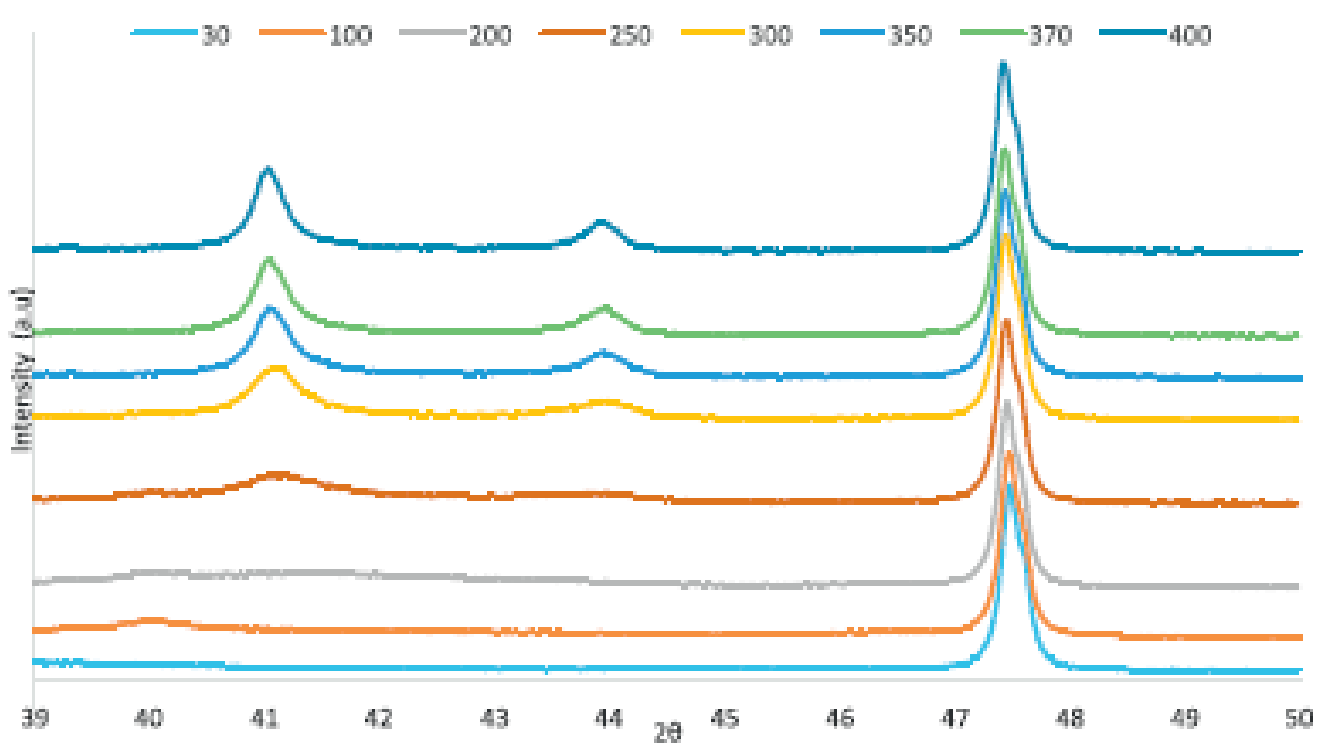

Fig. 4. XRD pattern obtained during reduction of PdZn_ZnO_COM at various temperatures $\left({ }^{\circ} \mathrm{C}\right)$, Large peak at $2 \theta-47.7^{\circ}$ is ascribed to $\mathrm{ZnO}(102)$ plane [29].

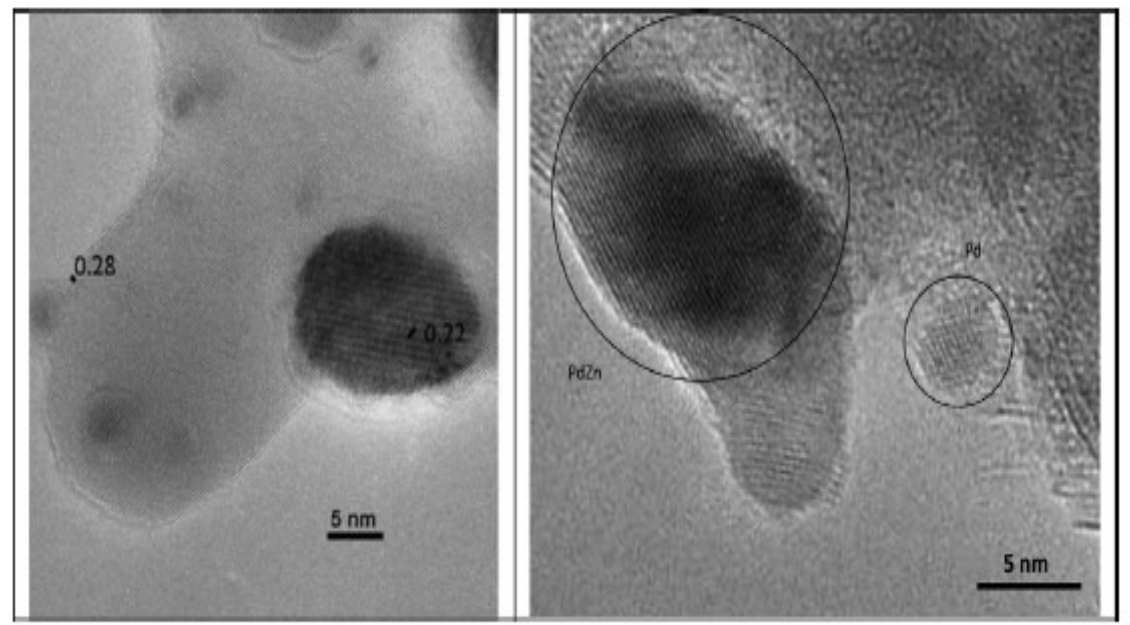

Fig. 5. Left: HRTEM image of a single polycrystalline PdZn particle supported on ZnO-H2. The lattice fringes of $\mathrm{PdZn}(101)$ and $Z \mathrm{nO}(100)$ are marked, Right: HRTEM image of single PdZn and Pd particles supported on ZnO_COM. 


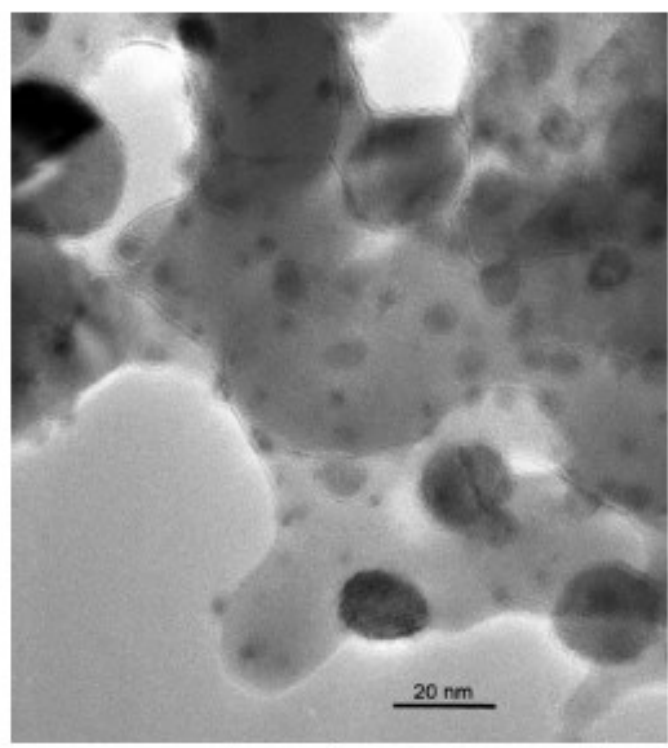

A

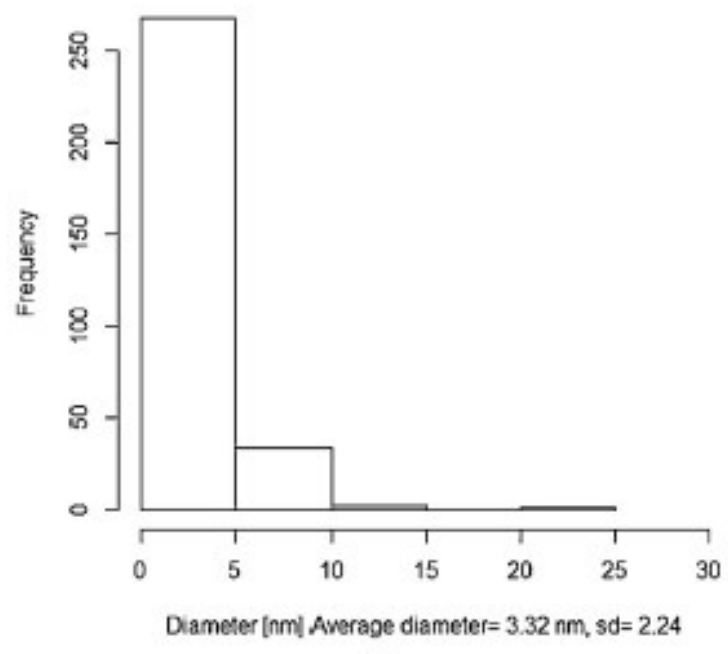

B

Fig. 6. (A) HRTEM image of $\mathrm{PdZn} / \mathrm{ZnO} \mathrm{H}_{2}$. (B) Particle size distribution of the same sample,
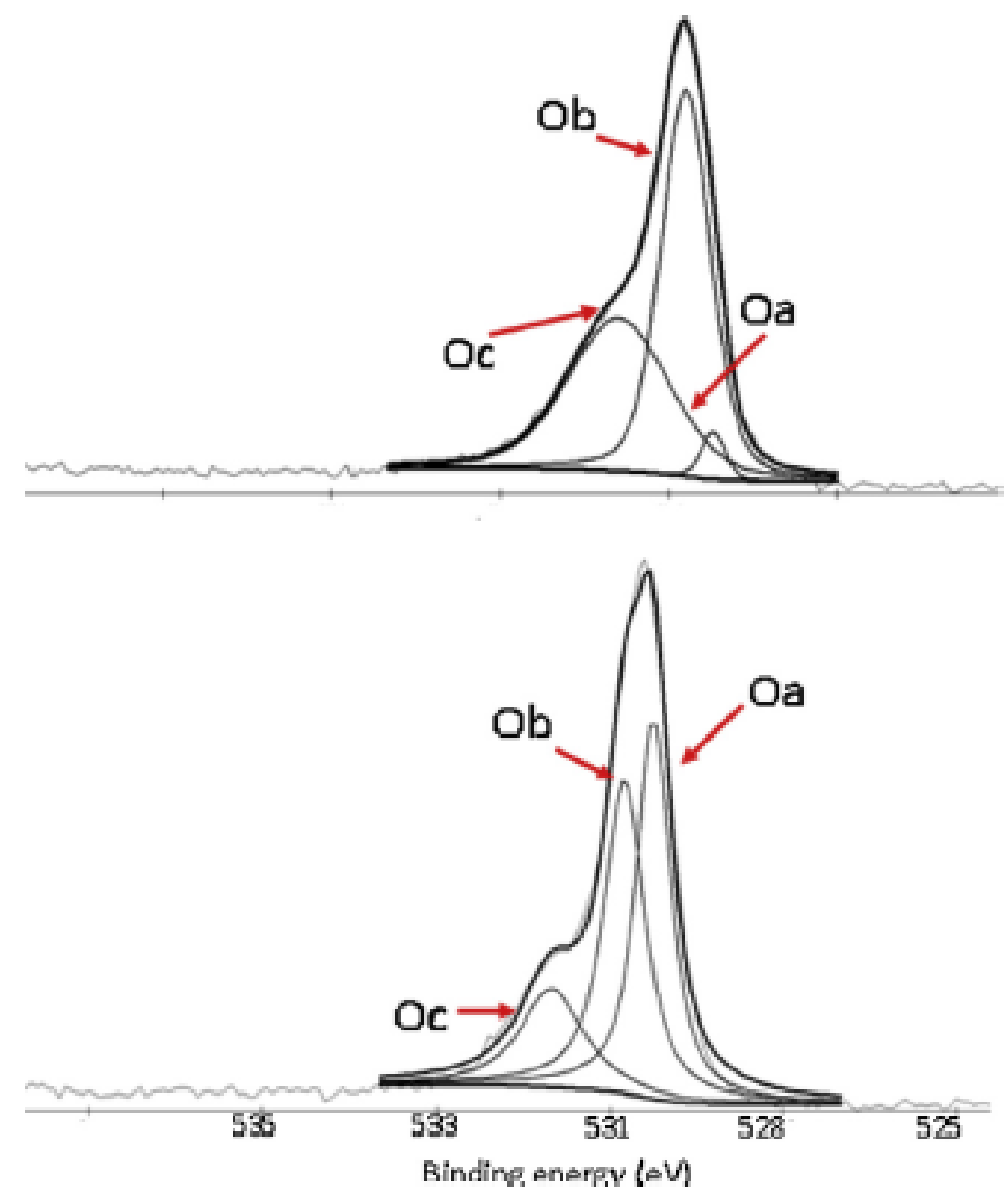

Fig. 7. Comparison of the 0 1s spectra of $\mathrm{PdZn} Z \mathbf{Z n O} \mathrm{H}_{2}$ (top) and $\mathrm{PdZn} \mathbf{Z n O} \mathrm{O}_{2}$ (bottom) with the assigned peaks from various oxygen species. 


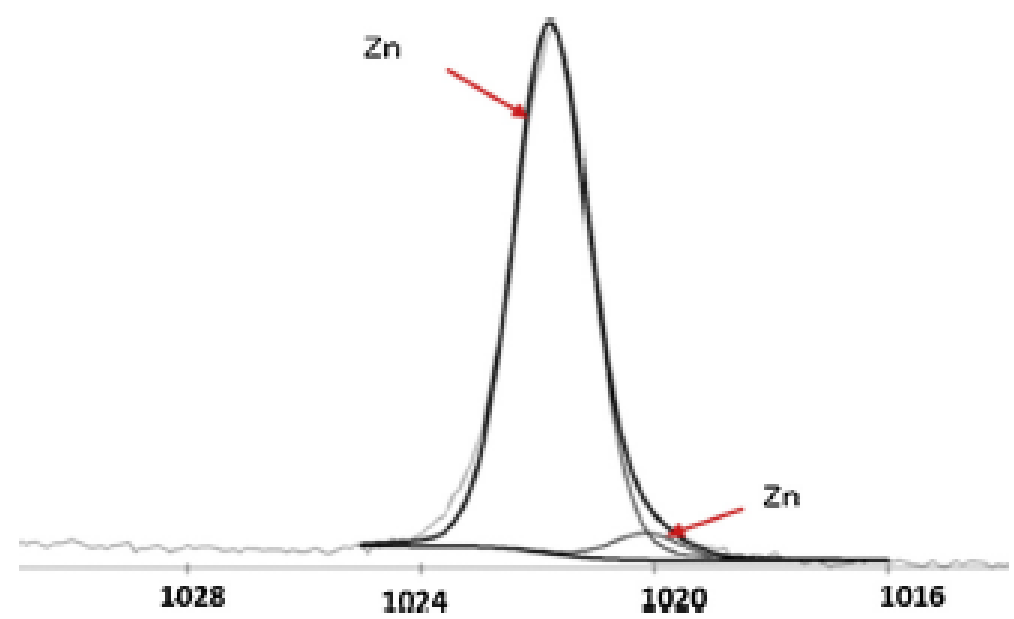

Fig. 8. Representative highly resolved core level $\mathrm{Zn}_{\mathrm{n}} 2 \mathrm{p}_{3 / 2}$ spectrum of PdZnZZnO_COM.

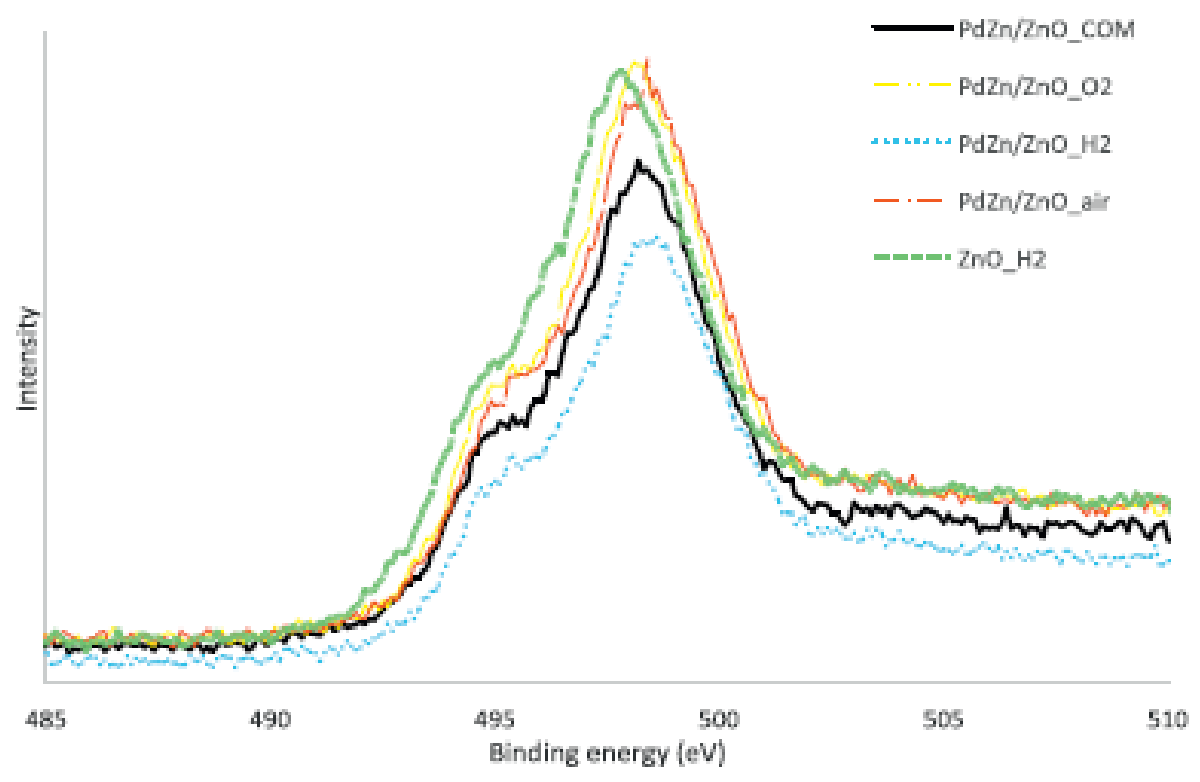

Fig. 9. The $\mathrm{Zn} \mathrm{LMM}$ line of $\mathrm{PdZn} / \mathrm{ZnO}$ catalysts as compared to pure $\mathrm{ZnO} \mathrm{H}_{2}$ support. 


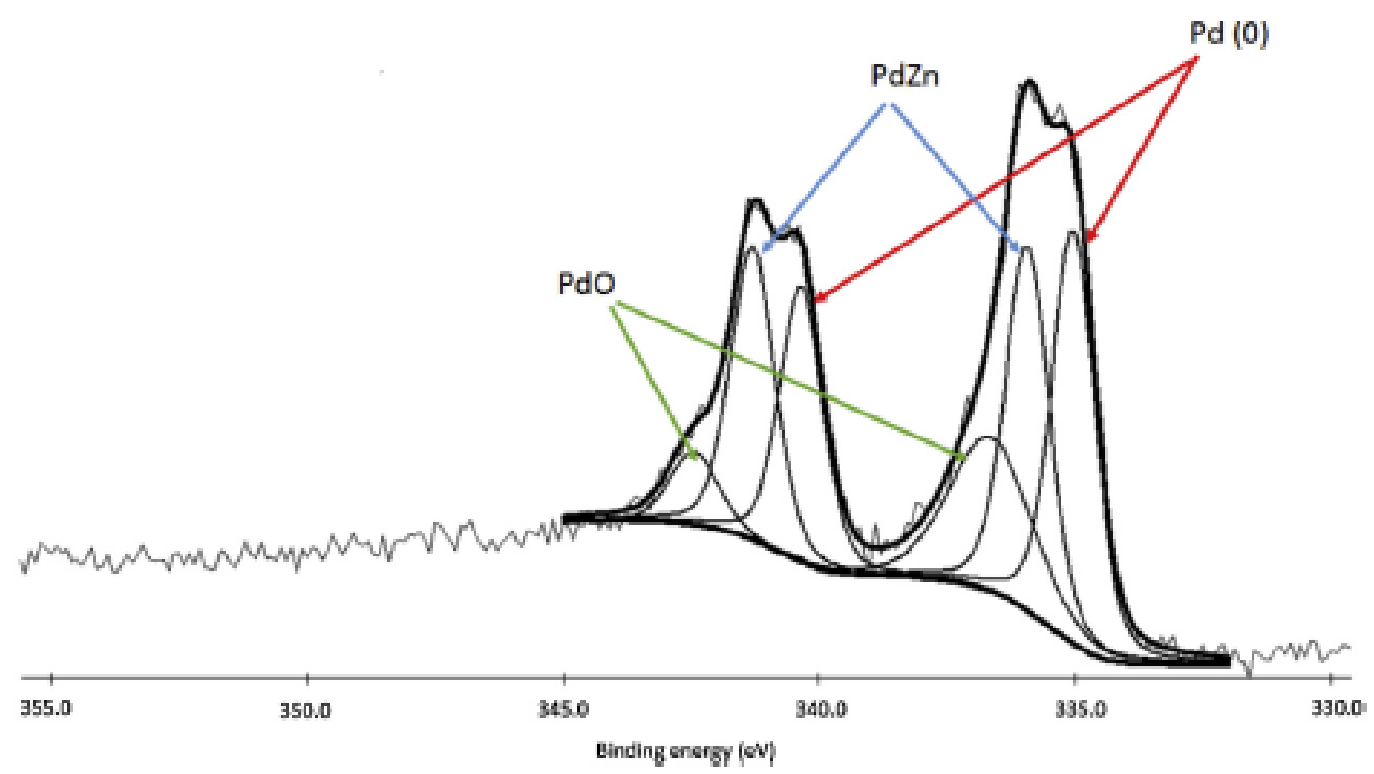

Fig. 10. Representative XPS spectra of the elemental peaks of Pd $3 d$ in $\mathrm{PdZn} / \mathrm{ZnO} \mathrm{H}_{2}$

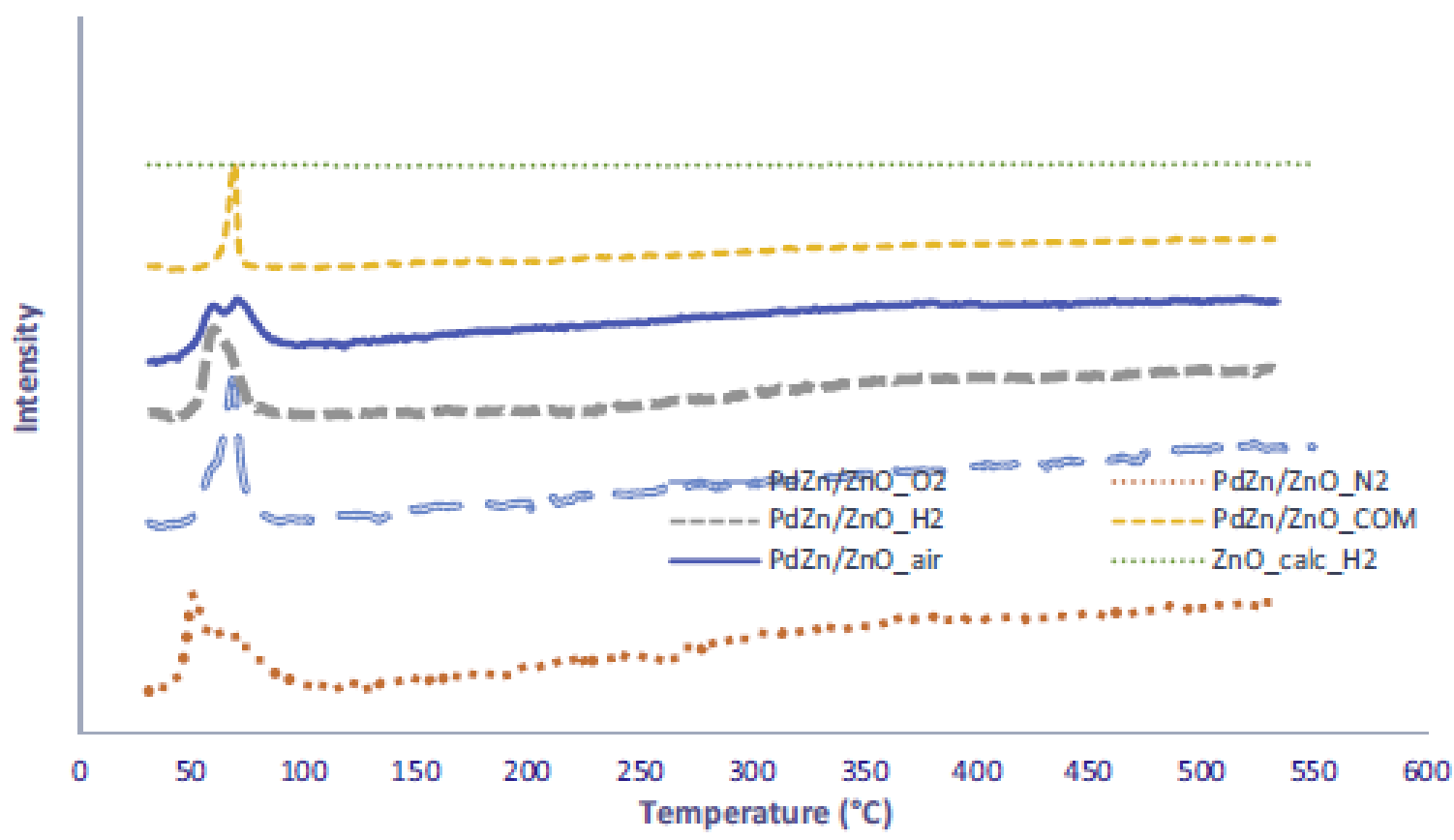

Fig. 11. $\mathrm{H}_{2}$-TPR profile of $\mathrm{ZnO} \mathrm{H}_{2}$ and $\mathrm{PdZn/ZnO}$ catalysts, 

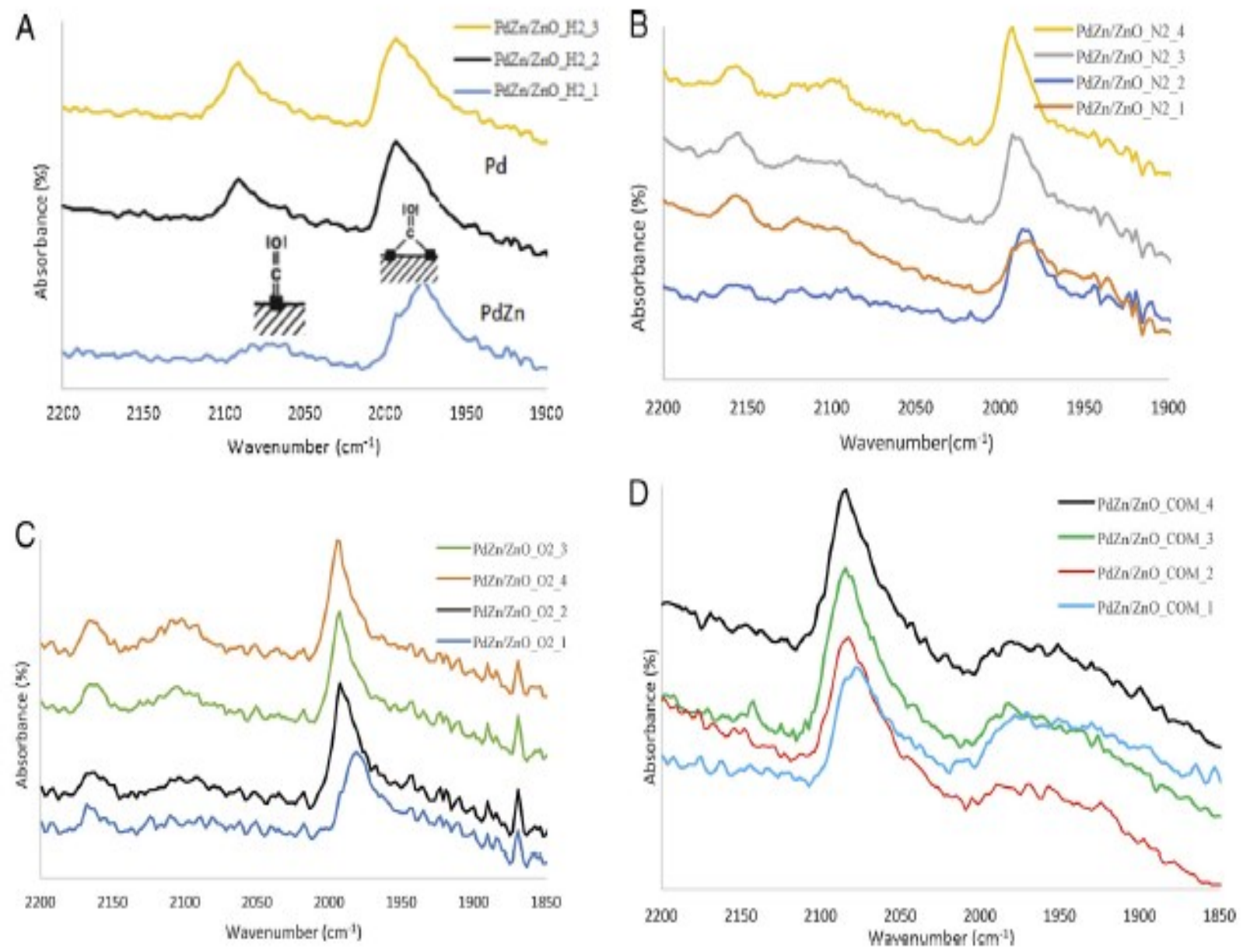

Fig. 12. $\mathrm{CO}$ adsorption at room temperature on (A) $\mathrm{PdZn} / \mathrm{ZnO} \mathrm{H} 2$, (B) $\mathrm{PdZn} / \mathrm{ZnO} \mathrm{N} 2$, (C) $\mathrm{PdZn} / \mathrm{ZnO}$ O2and (D) PdZn/ZnO COM. Spectra 1-4 were recorded with increasing time of $\mathrm{CO}$ exposure. 


\section{Table 1}

The physicochemical characterization of the $\mathrm{ZnO}$ supports studied.

\begin{tabular}{lll}
\hline Sample & BET surface area $\left(\mathrm{m}^{2} / \mathrm{g}\right)$ & Ratio $(100)(002)$ \\
\hline $\mathrm{ZnO} \mathrm{O}_{2}$ & 88 & 1.59 \\
$\mathrm{ZnO}$ Air & 76 & 1.56 \\
$\mathrm{ZnO} \mathrm{N}_{2}$ & 27 & 1.13 \\
$\mathrm{ZnO \perp H}$ & 24 & 1.3 \\
PdZnZnO_COM & 16 & 1.2 \\
\hline
\end{tabular}

\section{Table 2}

Catalytic performance of a series of PrZZn/ZnO catalyst in low temperature MSR together with corresponding particle size measured from HRTEM images,

\begin{tabular}{|c|c|c|c|}
\hline Sample & Activity $\left(\mu\right.$ mol $/\left(g_{m \rightarrow n} s\right)$ & CO concentration (ppm) & HRTEM particle size (nm) \\
\hline PdZn_FEUP_ $0_{2}$ & 42,6 & 1450 & 3.3 \\
\hline PAZn_FEUP_air & 46,8 & 1400 & 2.4 \\
\hline 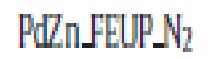 & 63.8 & 700 & 2,1 \\
\hline $\mathrm{Pd}$ dZnFFUP $\mathrm{H}_{2}$ & 87.9 & 146 & 3.3 \\
\hline$P A Z \cap Z n O C O M$ & 38.3 & 309 & 8,1 \\
\hline
\end{tabular}


Table 3

$\mathrm{BE}$ and relative intensities of components of 01 s XPS spectra.

\begin{tabular}{lllllll}
\hline Sample & Oa BE $(\mathrm{eV})$ & \% & Ob BE $(\mathrm{eV})$ & $\%$ & Oc BE $(\mathrm{eV})$ & $\%$ \\
\hline PdZn_ZnO_H & 530.2 & 4.6 & 530.7 & 52 & 531.9 & 43.4 \\
ZnO_H2 & 529.8 & 5.9 & 530.2 & 53 & 531.7 & 40.7 \\
PdZnZnO_O2 & 530.2 & 40.5 & 530.8 & 40.2 & 532.0 & 19.2 \\
PdZnZnO_COM & 530.4 & 66 & 531.6 & 11 & 532.3 & 23 \\
PdZnZnO_air & 530.5 & 58 & 531.1 & 19 & 532.1 & 22 \\
\hline
\end{tabular}

Table 4

BE and composition of Pd 3d XPS spectra of studied PdZn/Zn0 catalysts.

\begin{tabular}{|c|c|c|c|c|c|}
\hline Sample & $\mathrm{BE}(\mathrm{eV}) \mathrm{Pd} 3 \mathrm{~d}_{5 / 2}$ & $\mathrm{BE}(\mathrm{eV}) \mathrm{PdZn}$ & $\mathrm{BE}(\mathrm{eV}) \mathrm{Pd} 0$ & $\mathrm{Pd} 3 \mathrm{~d} / \mathrm{Zn} 2 \mathrm{p}$ & Composition (\%) Pd/PdZn/Pd0 \\
\hline $\mathrm{PdZn/ZnOCCOM}$ & 334,75 & 335.64 & 337.11 & 0,1 & $34 / 56 / 9$ \\
\hline PdZn/Zn0_air & 334.88 & 335.58 & 336.61 & 0,06 & $39 / 38 / 22$ \\
\hline $\mathrm{PdZn} / \mathrm{ZnO} \mathrm{H}_{2}$ & 335.04 & 335.93 & 336,66 & 0,12 & $29 / 51 / 19$ \\
\hline $\mathrm{PdZn} / \mathrm{ZnO} \mathrm{L}_{2}$ & 334.89 & 335,70 & 336,73 & 0,07 & $31 / 36 / 32$ \\
\hline
\end{tabular}

